\title{
Green Taxes in a Post-Paris World: Are Millions of Nays Inevitable?
}

\author{
Stefano Carattini ${ }^{1,2}$. Andrea Baranzini ${ }^{3}$. Philippe Thalmann ${ }^{4}$. \\ Frédéric Varone $^{5}$. Frank Vöhringer ${ }^{4}$
}

Accepted: 7 March 2017 / Published online: 23 March 2017

(C) The Author(s) 2017. This article is an open access publication

\begin{abstract}
Turning the Paris Agreement's greenhouse gas emissions pledges into domestic policies is the next challenge for governments. We address the question of the acceptability of cost-effective climate policy in a real-voting setting. First, we analyze voting behavior in a large ballot on energy taxes, rejected in Switzerland in 2015 by more than 2 million people. Energy taxes were aimed at completely replacing the current value-added tax. We examine the determinants of voting and find that distributional and competitiveness concerns reduced the acceptability of energy taxes, along with the perception of ineffectiveness. Most people would have preferred tax revenues to be allocated for environmental purposes. Second, at the same time of the ballot, we tested the acceptability of alternative designs of a carbon tax with a choice experiment survey on a representative sample of the Swiss population. Survey respondents are informed about environmental, distributional and competitiveness effects of each carbon tax design. These impacts are estimated with a computable general equilibrium model. This original setting generates a series of novel results. Providing information on the
\end{abstract}

The authors thank Sam Fankhauser, Anthony Leiserowitz and Boris Krey as well as the editors of this special issue, Cees Withagen, Gerard van der Meijden, and Rick van der Ploeg, for providing very valuable feedback. All authors acknowledge financial support from the Swiss Federal Office of Energy. Carattini acknowledges support from COST Action IS1309 "Innovations in Climate Governance: Sources, Patterns and Effects" (INOGOV) and from the Swiss National Science Foundation, grant P2SKP1_165028.

\section{Stefano Carattini}

s.carattini@1se.ac.uk

1 Yale School of Forestry and Environmental Studies, Yale University, New Haven, CT, USA

2 Grantham Research Institute on Climate Change and the Environment and ESRC Centre for Climate Change Economics and Policy, London School of Economics and Political Science, London, UK

3 Haute école de gestion de Genève, HES-SO/University of Applied Sciences Western Switzerland, Carouge, Switzerland

4 Swiss Federal Institute of Technology Lausanne - Ecole Polytechnique Fédérale de Lausanne (EPFL), Lausanne, Switzerland

5 Department of Political Science and International Relations, University of Geneva, Geneva, Switzerland 
expected environmental effectiveness of carbon taxes reduces the demand for environmental earmarking. Making distributional effects salient generates an important demand for progressive designs, e.g. social cushioning or recycling via lump-sum transfers. The case of lump-sum recycling is particularly striking: it is sufficient to show its desirable distributional properties to make it one of the most preferred designs, which corresponds to a completely novel result in the literature. We show that providing detailed information on the functioning of environmental taxes may contribute to close both the gap between acceptability ex ante and ex post and the gap between economists' prescriptions and the preferences of the general public.

Keywords Carbon taxes - Acceptability · Political economy · Ballot data - Choice experiment

JEL Classification: D72 · D78 · H23 - Q54

\section{Introduction}

During the last decades, countries and international organizations have struggled to define a system of global governance able to tackle climate change. The Kyoto Protocol spurred the adoption of a first generation of climate policies (Fankhauser et al. 2015), but much more effort is required to meet the challenge of climate change mitigation (IPCC 2014). Unilateral policies have emerged to partly compensate for the continued failure of international negotiations (Ostrom 2009; Jordan et al. 2015), but only a fraction of countries opted for energy and carbon taxes (Baranzini and Carattini 2014; World Bank 2014). Most countries went for "soft policies" such as subsidies for renewable energies, which in some cases turned up to be not only strongly regressive but also extremely expensive (Marcantonini and Ellerman 2014). Vested interests and the general unpopularity of taxes are the main reasons behind this political choice.

The developments related with the 2015 Conference of Parties to the United Nations Framework Convention on Climate Change and the Paris Agreement have created a major breakthrough in the international negotiations for climate change mitigation. However, countries' emissions pledges are not credible policy commitments. The world is at a turning point: strong domestic policies are now necessary to meet the Paris pledges at a reasonable cost. Any other outcome is likely to put the pledge-and-review system under pressure and to jeopardize the future tightening of current pledges (Baranzini et al. 2015).

How to overcome resistance to energy and carbon taxes is thus of primary interest. A recent literature has attempted to provide a first set of explanations to the lack of public support for environmental taxes. Real ballots on environmental taxes take place sporadically, and so real voting behavior is hard to observe. As a result, the existing literature generally relies on primary data from stated preference surveys, and revealed preference studies in controlled settings. These studies are usually realized in neutral times, i.e. absent any political campaigning. However, vested interests and media coverage are very powerful drivers of public opinion on environmental matters (Sampei and Aoyagi-Usui 2009; Jacobsen 2011; Spash and Lo 2012).

On March 8, 2015 the Swiss population was called to vote on a popular initiative aiming at replacing the current value-added tax (VAT) with an energy tax. About 2.2 million voters expressed their opinion. The proposal was rejected by a large majority, $92 \%$ of voters. Right after the ballot, a survey was administered to a representative sample of the Swiss popula- 
tion, to explain the observed voting behavior. This strategy allows us to compare our sample with the observed outcome and obtain information on the extent of misreporting, if any. At the same time, we administered a choice experiment to another representative sample of the Swiss population, taking advantage from the very specific timing to assess the acceptability of alternative tax designs in presence of high political salience. In using this real context, we build on a common finding in the stated preference literature, which suggests that respondents with experience with a given type of decision tend to provide more reliable answers. In this case, our sample has prior experience with the voting system in Switzerland, and the specific timing of the survey implies that they can also have experience on climate policy issues. In the choice-experiment setting we consider a carbon tax with four different tax rates and five revenue recycling options: income tax rebates; reduction of the value-added tax; lump-sum transfers; social cushioning; and earmarking for additional emission abatements through the purchase of international carbon offsets. Respondents face three alternatives: two different carbon tax designs, and the status quo. Hence, we reproduce the situation of real ballots, in which voters are asked to express their opinion on different proposals, with of course the possibility to reject all of them (see Kriesi 2005). We exploit the results of a general equilibrium modeling exercise to inform respondents on the expected outcomes of each carbon tax design in terms of energy price increases, emission abatements, overall economic effects and distributional impacts. In this way, we address some of the most recurrent obstacles to the popularity of carbon taxes, all of which are arguably driven by imperfect information: excessive fear of adverse competitiveness and distributional effects, perceived environmental ineffectiveness and misunderstanding of revenue neutrality. Our novel approach uses a large sample of representative individuals, while providing detailed information on the functioning of carbon taxes, and transparent figures on the consequences that each decision would have. Our approach thus aims at combining the benefits of surveys and experiments. The contribution of both methods has been substantial in this literature, and we build on the lessons learnt with both. To the best of our knowledge, this is the first time such a methodological approach is used.

Our study is of interest for all democratic settings, direct or indirect. We use Switzerland as a laboratory of study, but the divergence between economists and the general public on the benefits of environmental taxes is a recurring obstacle to environmental tax reforms all around Europe (Dresner et al. 2006). The unpopularity of carbon taxes has hampered their implementation in France (Deroubaix and Lévèque 2006), while fear of competitiveness effects led to massive exemptions in Scandinavian countries, decreasing the potential for any sizeable environmental effect (Baranzini and Carattini 2014). Similar obstacles seem to reduce the popularity of carbon taxes in emerging economies, too (Gevrek and Uyduranoglu 2015). Recent voting in the United States (Washington State) provides further support to the idea of a widespread resistance to carbon taxes.

Data on voting behavior shows that the chances of the 2015 popular initiative rejected in Switzerland would have been much higher if tax revenues had been earmarked for environmental purposes rather than for replacing the VAT, everything else equal. Concerns about the effect of higher energy prices on the distribution of income as well as on the competitiveness of firms are among the main determinants of rejection. People are also generally skeptic about the potential change in behavior that energy taxes could generate.

The design of our choice experiment addresses all these concerns and shows that information provision can lead to very different results from those in the literature. Estimations from our modeling scenarios suggest that all carbon tax designs under investigation imply limited competitiveness effects and all provide significant reductions in emissions. Using the full tax revenues to purchase foreign offsets allow for massive emission abatements. Most 
recycling options imply slightly regressive effects, except for lump-sum transfers and social cushioning, which (the latter by design) lead to a net progressive effect.

A common finding in the literature is that people are most willing to accept a carbon tax if its revenues are used to strengthen its environmental effectiveness, which people believe to be small. This stylized fact is confirmed by our analysis of voting behavior. However, our choice-experiment setting, by informing on the emissions reduction associated with the different carbon taxes, allows closing the gap between (possibly low) perceived effectiveness and (higher) predicted effectiveness. As a result, we find that earmarking for additional abatements is no longer particularly attractive. Information on the scenarios' predictions renders instead lump-sum transfers and social cushioning particularly popular, by making salient their progressive properties. The finding for lump-sum transfers is particularly striking. Despite their minimal administrative burden and the ability to address distributional concerns (Baranzini et al. 2000; Metcalf 2009), lump-sum transfers are especially neglected by the literature on the acceptability of carbon taxes. The reason for this is that these properties may not be perceived by the population, along with revenue neutrality. Our setting shows however that it is sufficient to provide people with some supplementary information to reduce the gap between their preferences and economists' prescriptions.

We find that recycling through income tax rebates is relatively unpopular, as often found in the literature. People do not seem to understand the concept of environmental tax reform, or at least they do not see its advantages as some economists do. We stress that our modeling scenarios do not suggest the existence of a significant double dividend, i.e. positive economic effects through the reduction of distortionary taxes. Reductions in the value-added tax perform similarly poorly, in terms of acceptability. We also find that the support for green taxes decreases linearly with the rise in the tax rate. If we use our choice experiment to simulate the level of acceptability of the popular initiative voted on March 8, 2015, we obtain a figure that is very consistent with the observed real outcome, indicating a high external validity of the results based on our choice experiment.

We contribute to the literature on the acceptability of carbon taxes by shedding new light on the obstacles to the acceptability of carbon taxes. We make the voting decision in the choice-experimental setting as realistic as possible and provide people with sufficient details to take an informed decision on carbon taxes. Our results show that making the effect of environmental taxes salient can contribute to render relatively unpopular designs much more popular. We relate this result to a recent finding in the literature suggesting that experiencing the functioning of a given policy design allows citizens to revise their beliefs on the effectiveness and fairness of environmental taxes, which by default tend to be overly pessimistic (cf. e.g. Carattini et al. 2016). Our approach thus provides an alternative to the use of trials that has been increasingly called for to remedy environmental taxes' lack of popularity (Sælen and Kallbekken 2011; Cherry et al. 2014; Carattini et al. 2016). With a careful design and detailed information, acceptable carbon taxes can be implemented at a moderately high tax rate, and sustain credible climate policies.

\section{Context}

\subsection{Literature Review}

The theoretical literature on the political economy of environmental policy mostly focuses on lobbying by energy-intensive industries (see Oates and Portney 2003 for a review). Yet, 
Kirchgassner and Schneider (2003) stress the importance of considering voters' preferences, and how their pure economic objectives may compete with other interests, including environmental preferences. The opinion of the general public may however be biased by media, and captured by vested interests, possibly leading to inaccurate opinion formation and policymaking (Millner and Ollivier 2016). But citizens can also organize in environmental advocacy groups and play an active role in the political arena. The model of Marchiori et al. (2017) shows that the presence of green lobbies influencing policy-makers may contribute to increase the stringency of environmental policy, as well as the likelihood of a stable coalition in environmental agreements.

The theoretical literature usually takes a narrow perspective and presumes that people rarely vote on policies, but rather for candidates and parties. The empirical literature has instead taken a broader perspective, assessing for instance the private willingness to pay for climate change mitigation (see Nemet and Johnson 2010 for a review), as well as the acceptability of specific policies. The case of environmental taxes has received particular attention. So popular among economists for reasons of efficiency and environmental effectiveness (Baranzini et al. 2015) and so unpopular among the general public, environmental taxes represent a unique opportunity to study the consequences of informational asymmetries between citizens, policy-makers and experts.

Empirical economists have used a wide range of tools to understand the determinants of energy taxes' acceptability. Qualitative assessments using focus groups have helped understanding the obstacles to the European Environmental Tax Reform (Dresner et al. 2006) and to environmental taxes more generally (Kallbekken and Aasen 2010). Qualitative surveys have also been used to orient quantitative surveys, as in Baranzini and Carattini (2017).

The focus groups of Dresner et al. (2006) revealed the high level of distrust in environmental tax reforms among the general public. The general public seems to underestimate the effectiveness of environmental taxes and to perceive them mainly as an excuse for raising additional public revenues. People may only be willing to support their introduction if revenues are clearly earmarked for environmental purposes. They also wonder how environmental taxes could green the economy if revenues were to be redistributed. Moreover, they raise fears of adverse competitiveness and distributional effects.

These findings from small samples have been confirmed by larger surveys. Steg et al. (2006) interviewed about one hundred respondents in the Netherlands on the perceived effectiveness and acceptability of energy subsidies and taxes. They find subsidies to be much more effective, at least in people's eyes. "Pull measures" (i.e. subsidies) are seen as incentives driving a voluntary change in behavior, whereas taxes are felt as coercive measures imposing a change in behavior, and thus facing people's resistance. Taxes can however be perceived as effective if revenues are earmarked for environmental purposes. In terms of acceptability, instruments and designs that are perceived as effective (i.e. subsidies) overperform those that are not (i.e. taxes). Similar results are provided in Kallbekken and Sælen (2011). Based on a Norwegian sample, the authors find that perceived ineffectiveness of fuel taxes represents a major obstacle to acceptability. In this respect, Baranzini and Carattini (2017) find that acceptability depends on the expectation of both primary and ancillary benefits. Earmarking revenues for environmental purposes contributes to reduce the hostility to a carbon tax, as well as renaming it "climate contribution".

The potential of standard surveys is however limited, in particular when respondents are required to deal with complex issues such as the design of carbon taxes. A few authors have thus opted for choice experiments, which allow focusing on the internal validity and thus reduce the room for bias related to hypothetical answers. Bristow et al. (2010) analyze the acceptability of personal carbon trading schemes and carbon taxes with a sample of about 300 
individuals. They compare different tax rates and modes of recycling and find for instance that tax thresholds perform particularly well in terms of acceptability. Thresholds can indeed reduce the regressive effects of carbon taxes, similarly to lump-sum recycling. While the authors call for the use of larger samples to support their findings, they suggest that acceptable carbon tax designs are not a chimaera. Sælen and Kallbekken (2011) show, with a choice experiment, that the chances for carbon taxes to be acceptable are higher with earmarking for environmental revenues. With this type of recycling, the Norwegian population would agree to increase the current fuel tax rate by about 15\%. Brannlund and Persson (2012) also use a choice experiment to test different designs for a carbon tax. The labeling of the tax changes randomly with the other attributes and the authors find that even labeling it "other" is better than using its real name, "tax". Progressive designs are also preferred to regressive ones. Gevrek and Uyduranoglu (2015) extend the analysis of the acceptability of carbon taxes to emerging economies with a choice experiment in Turkey. While their setting does not allow measuring the overall level of acceptability of hypothetical Turkish carbon taxes, their empirical exercise provides very similar findings to the literature in developed countries, including the preference for progressive schemes, for earmarking of revenues and for low tax rates.

Choice experiments contribute to tackle the issue of hypothetical bias. However, inference is still based on stated preferences. Revealed preferences are elicited in lab experiments, but issues of external validity may arise if the general public behaves differently than the sample participating in the experiment (Harrison and List 2004). In many cases, however, lab experiments can perform relatively well in terms of external validity, while, at the same time, providing the advantage of a controlled environment, in which the experimenter can create a microeconomic system that mirrors the real world, and in which the decisions that subjects take determine their financial payoff (see Alm et al. 2015; cf. also Falk and Heckman 2009). Providing detailed (or "full") information is also possible in this context, and payoffs are generally transparent. Some examples of lab experiments are available in this literature. For instance, Kallbekken et al. (2011) provide experimental evidence in favor of tax aversion and of the demand for earmarking of Pigouvian tax revenues. They show that efficiency and acceptability may conflict even when real stakes are involved, i.e. participants do not necessarily prefer the policy that is pay-off maximizing (see also Kallbekken et al. 2010). Labeling carbon taxes as "fee" helps to reduce tax aversion. The experiment of Cherry et al. (2012) supports these findings and also provides support for those of Steg et al. (2006). In particular, the authors show that "non-coercive" instruments such as subsidies (and even quotas) are much preferred to carbon taxes, so that policy-makers betting on carbon taxes may end up with the status quo. In the authors' words, inefficient "half measures" are more likely to be politically feasible than efficient "full measures". Cherry et al. (2014) allow subjects in a market with externalities to vote on the introduction of Pigouvian taxes, including after having experienced the policy in a trial period. Trial periods increase the acceptability of the policy that subjects are allowed to experiment. Tiezzi and Xiao (2016) also design a market with an externality, but in their framework addressing this externality with a tax may not have an immediate effect. With such intertemporal context, they show that the delay in experiencing the benefits from taxation reduces the support for this instrument. They motivate this finding with the complexity of the situation in which subjects have to take their decisions, doubting the plausibility of extremely high discount rates.

These methods are generally used as imperfect substitutes for the observation of real ballots on environmental taxes, which are unthinkable in some countries and very rare in others. A few opportunities to study voting behavior on environmental matters already occurred in the United States or Switzerland, even though not exclusively on environmental taxes (see 
Deacon and Shapiro 1975; Fischel 1979; Kahn and Matsusaka 1997; Fort and Bunn 1998; Salka 2001; Kahn 2002; Stadelmann-Steffen 2011). An exception is Thalmann (2004), who analyzes three energy tax proposals voted and rejected by the Swiss population in 2000. While all proposals failed, two were really close to the majority threshold. Differences in the use of revenues (earmarking for subsidizing renewable energy versus redistribution), and in the tax rates, are shown to potentially contribute to the small differences in the rate of approval between the revenue-neutral "Green tax reform" (44.6\% of yes-votes) and the "Energy conservation package" (46.6\%). The third alternative, the "Solar initiative" (31.9\%), proposed to earmark half of the revenues for solar energy, and the other half for energy conservation. Differences in the socio-economic and geographic characteristics of voters explain within-proposal variation (Halbheer et al. 2006; Bornstein and Lanz 2008).

\subsection{Local Context}

On March 8, 2015, the Swiss population voted on a popular initiative launched by the Green Liberal Party aiming at replacing the current value-added tax with a tax on non-renewable energy. ${ }^{1}$ The Swiss government and all other parties but the Green Party were against the initiative. In spite of the initiative's low probability of success, the business organizations invested important efforts in a campaign emphasizing the potential drawbacks of such a proposal.

The main arguments in favor of the initiative were:

- It taxes dirty energy sources, making renewable energy sources competitive without subsidization and allowing for a transition towards a more sustainable economy

- It ensures fiscal neutrality, by keeping both the revenues for the government and the overall tax burden unchanged

- It rewards environmentally-friendly consumers, by allowing them to save money on the VAT

- It strengthens the local economy by reducing its dependence on oil producer states and by inciting green innovation in Switzerland

- It saves costs to firms by eliminating the administratively burdensome VAT

The government shared in principle all these objectives, but not the mean to achieve them as proposed by the initiative. In February 2015, Switzerland was the first country to submit a pledge to the United Nations Framework Convention on Climate Change's pledge-and-review system. It pledged to reduce greenhouse gas emissions by $50 \%$ by 2030 with respect to the levels of 1990. However, the Swiss government opposed the intention to completely erase the VAT and replace it with an environmental tax, which is supposed to over time reduce energy consumption, i.e. its own tax base. The government stressed that the VAT revenues represented its main source of funding, and that a relatively high tax rate would have been necessary to raise the same revenues of the VAT with an energy tax. During the debate, a potential price of 5 Swiss francs (CHF) per liter of gasoline was mentioned, i.e. a trebling of current prices. This scenario was rapidly appropriated by the political parties and organizations opposing the initiative. The government also mentioned a series of concerns related with the competitiveness and distributional effects of the proposed reform. The argument about the threat to competitiveness resonated particularly strongly in that specific period, which followed by a few weeks only the decision of the Swiss National Bank to drop its euro peg.

1 The maximum rate of the VAT is $8 \%$. On the same day, the population also voted on a popular initiative of the Christian Democratic People's Party of Switzerland aiming at increasing fiscal exemptions for families with children. This initiative was rejected at $75.4 \%$. 
The ensuing appreciation of the Swiss franc was at the time expected to put under extreme pressure the many export-oriented sectors of the Swiss economy.

The popular initiative was rejected at $92 \%$. The Swiss government did not formulate a counter-proposal, but a few weeks after the ballot announced its strategy to meet the abovementioned pledges as well as to phase out nuclear energy (the so-called "Energy Strategy 2050"). This strategy is still valid and consists of higher taxes on electricity and heating fuels. Transport taxes are also expected to be taxed, but only after a period of adaptation. We note that Switzerland introduced a carbon tax in 2008 , but only on heating and process fuels. The current tax rate is $84 \mathrm{CHF} / \mathrm{tCO}_{2}$.

\section{Methodology}

\subsection{Analysis of Voting Behavior}

Since 1977, the Swiss Centre of Expertise in the Social Sciences conducts the VOX survey after each federal ballot. 1500 persons are interviewed. We use these data to assess the determinants of voting behavior on the March 8 vote on the energy tax. VOX data are widely used to analyze voting behavior on different matters, as they perform well in terms of representativity and may not present in their full extent the weaknesses of pure statedpreference studies. We took advantage of the strong presence of energy issues in the media at the time of this ballot to administer a second survey. It uses a choice experiment format to elicit the acceptability of alternative energy tax designs (see below). Both surveys were carried out between March and May 2015.

In Switzerland, the rejection of a popular initiative is rather the rule, and not the exception. From 1891 to date, 9 out of 10 popular initiatives were rejected at the ballot box (sometimes after having influenced the legislative process). However, the rejection rate for this initiative is the second highest since 1891, the highest since 1929. This high rejection rate implies that voters from all government parties have contributed to reject the initiative, including the political left. The participation rate $(42 \%)$ was slightly below the average participation rate for all popular votes during the period 1991-2014 (43.7\%), the importance of the issue at stake being relatively low compared to the average ballot, including hotter energy issues such as nuclear phasing-out.

\subsection{Choice-Experiment on Alternative Designs}

\subsubsection{Survey Setting}

Not all designs can be subject to vote. Previous research has shown the importance of the policy design for acceptability and it is thus crucial to have information on different policy attributes and the combination thereof. The only way to obtain such information from a relatively large sample — that is, larger than what is usually available in the laboratory —is to rely on stated preferences. It is however possible to set up a survey in a way that it makes choices and trade-offs the most realistic possible, such as with a choice experiment.

A choice experiment design allows putting the consumer, or voter, in a real-life situation and, thus, reduces the hypothetical bias. In this case, we also leverage on the fact that our respondents, as Swiss residents, are in general familiar with the mechanisms of direct democracy, and are also familiar with the particular issue at stake, given the timing of the choice experiment. An important literature has shown that stated preference studies tend to perform 
Table 1 Choice experiment: attributes and levels

\begin{tabular}{ll}
\hline Attributes & Levels \\
\hline Tax rate $\left(\mathrm{CHF} / \mathrm{tCO}_{2}\right)$ & 60 \\
& 90 \\
& 120 \\
& 150 \\
Revenue recycling & Income tax rebates \\
& VAT rebates \\
& Lump-sum transfers \\
& Social redistribution \\
& Environmental earmarking \\
\hline
\end{tabular}

better, and thus be more reliable, when respondents have prior experience with the type of decision analyzed in the study (cf. e.g. Boyle et al. 1993; Whitehead et al. 1995; Cameron and Englin 1997; Czajkowski et al. 2015).

Furthermore, most of the focus is on the internal validity driven by the comparison of different designs. In our choice experiment, we present all respondents with three potential choices: two carbon taxes with two different designs and the status quo. By giving to respondents the possibility to reject all proposals, we are able to measure not only the relative preference for a given policy attribute, but also the overall likelihood that a carbon tax can be accepted. The design of the proposed carbon taxes is the result of the combination of two attributes: the tax rate, measured in terms of Swiss francs per ton of $\mathrm{CO}_{2}$ emitted, and the use of the tax revenues (see Table 1). Each respondent is requested to select one of the three options in 8 different hypothetical ballots, with the attributes being randomly combined at each time. To increase precision in the identification of the attributes' effects, respondents are given one of the 15 randomly-generated versions of the questionnaire.

As all combinations included in the choice experiment were previously part of a modeling exercise, we are able to provide respondents with information on the order of magnitude for the expected impacts on the following items of each carbon tax design:

- Price of gasoline, diesel and heating fuel

- $\mathrm{CO}_{2}$ emissions. When revenues are used to strengthen the environmental impact of the policy, we assume that international offsets are purchased and we thus also estimate the effect on carbon emissions abroad. We express this reduction in relative terms with respect to the emissions of Switzerland

- Purchasing power of the average Swiss household, based on a proxy for overall consumption

- Purchasing power of the average low-income household

We provide realistic numbers based on scenarios for 2020 from a dynamic multi-sectorial multi-household general equilibrium model of the Swiss economy, called GENESwIS (see Vöhringer 2012). ${ }^{2}$ For a range of uniform carbon taxes of $60-150 \mathrm{CHF} / \mathrm{tCO}_{2}$, the model predicts domestic emission reductions of 5-15\%. Impacts on total consumption are generally

2 In GENESwIS, households are disaggregated according to living standards and composition. Households and firms act rationally under perfect foresight and competition, and the government collects taxes and uses the revenue for public goods provision and social benefits (equal yield is assumed). Further standard features include international trade with an Armington assumption, labor-leisure choice, and a putty-clay representation for capital. GENESwIS is based on the 2008 energy related disaggregation of the Swiss Input-Output Table (Nathani et al. 2011), combined with the population census of the Swiss Federal Statistical Office 
negative, up to $-0.5 \%$ for a tax rate of $150 \mathrm{CHF} / \mathrm{tCO}_{2}$ combined with environmental recycling. As a notable exception, a small double dividend can be found for recycling through reductions of marginal income tax rates. Pure tax reforms with proportional rate reductions are regressive, and income tax recycling is the most regressive of the simulated variants. In contrast to this, lump-sum recycling renders the reform clearly progressive. International carbon offsets are cheap at the moment, and even very conservative assumptions allow for very sizable additional abatement abroad when carbon tax revenues are used for purchasing offsets.

The aim of this simulation is to provide sufficient information for the most relevant variables that are supposed to guide voting behavior, replicating the effort that a government could do to introduce environmental taxes to the population. Since we carefully explain to respondents the functioning and effects of carbon taxes, we expect this specific setting to lead to different results with respect to what is most often found in the literature.

The recruitment of participants went as follows. A set of about 4000 potential respondents was randomly selected and received by post the following material:

- A letter presenting the study, making all participants familiar with the issue and encouraging them to participate in the survey if called by phone, following the guidelines of Harrison and List (2004)

- A detailed one-page fact sheet explaining how carbon taxes work and the main implications of each recycling option

- The full set of choice cards for all 8 votes displaying the attributes and related impacts as estimated by the computable general equilibrium model (see Fig. 3 for an example)

A randomly drawn sub-set of the about 4000 potential respondents was then contacted by phone and driven through the questionnaire. In total 1200 individuals were interviewed. ${ }^{3}$ When it came to take a decision on the hypothetical ballots, all respondents were read a short and unique text describing the effects of each carbon tax type. This ensured that all respondents were provided with the same information, even those who had not spent time reading the material that they had received at home. As many already "voted" at home, respondents were given the possibility to skip the oral explanations. ${ }^{4}$

\subsubsection{Preferences for Attributes of Carbon Taxes}

Before identifying the determinants of individual support for a carbon tax, we hypothesize what they could be, based on our literature review:

\section{Footnote 2 continued}

(cf. Ecoplan 2012). Core elasticities of substitution that are relevant for carbon abatement have been taken from Mohler and Müller (2012).

3 The actual response rate was however about $75 \%$. We contacted by mail 4000 potential respondents, but only about 1600 had to be contacted by phone to reach the quota of 1200 observations. The response rate is thus relatively high, which helps to mitigate potential self-selection issues (see also next section). We believe that there are three main reasons for this high response rate. First, as suggested by Harrison and List (2004), an official invitation to participate in the study, as sent to each respondent, is likely to increase the response rate. Second, the salience of the topic is also likely to have contributed to increase the interest in our study. Third, the survey was administered by a marketing firm whose policy is to contact even 15 times the same phone number, until receiving an answer, to minimize issues related with selection.

4 In Switzerland, people may be asked to vote four times a year. A few weeks before the day of voting, all potential voters receive by post written information about the ballot, so that they have the time to form their opinion and also vote by correspondence if wishing so. Our choice experiment is thus organized in a way that matches standard ballot procedures. We emphasize that information on proposed policies circulates widely also in democratic countries that do not use the instruments of direct democracy, even though in different forms. 
Hypothesis 1 Tax rate We expect higher tax rates to lead to lower acceptability for carbon taxes, everything else equal

Hypothesis 2 Revenue recycling We expect acceptability to vary substantially depending on the use of revenues. We expect use of revenues for environmental purposes to increase acceptability the most, followed by social cushioning addressing potential distributional effects. We expect lower acceptability with the other recycling modes. Taxing here and reducing taxes elsewhere is usually a criterion that the taxpayers do not request, or understand. This is particularly true in the absence of a double dividend. We do not have specific priors on the relative ranking among income tax rebates, VAT reductions and lump-sum transfers

\section{Empirical Results}

\subsection{Analysis of Voting Behavior}

The VOX survey mainly consists in a standard list of questions, unchanged from ballot to ballot, to which are added additional questions specific to each ballot (two were added on our request). Table 2 presents the main outcomes for our analysis along with other main variables of interest (see Table 7 for descriptive statistics on the characteristics of our VOX respondents, Table 8 for those of the choice-experiment sample and Table 9 for those of the underlying population). As usual, the VOX ballot performs relatively well in predicting the ballot outcome. The frequency of no-votes in the survey, $90 \%$, is indeed very close to the real outcome $(92 \%)$. The survey overestimates instead to some extent participation, which was in reality $42 \% .{ }^{5}$ We model participation below, along with the voting decision. Table 2 displays additional interesting statistics. For instance, we observe that most people take their decision on the vote on average 16 days, or about 2 weeks, before the ballot day. Only about $20 \%$ declare to have a set opinion from the start. This shows the importance of studying political acceptability in the presence of media coverage and political debates, to capture the effect of (partisan) information on voters. Knowledge of the initiative is tested directly by the interviewers, based on an open question introducing the questionnaire.

The survey covers three arguments in favor, and three arguments against the initiative. These questions are asked only to respondents having participated in the ballot, and not to the full sample. Respondents can state their agreement or disagreement with such statements on a 1-4 Likert scale. The higher the score, the higher the agreement. In general, and not surprisingly comparing with the ballot outcome, arguments against the initiative score substantially higher than those in favor. In line with the literature, high concern is expressed for the competitiveness and distributional effects potentially generated by the implementation of the proposal. Another argument widely used by the opponents was that over time a decreasing tax base would have systematically implied higher tax rates, and so larger effects on the price of energy, on competitiveness and on the distribution of income. This argument also seems to have been well understood by the public. Consistently, the pro argument emphasizing rev-

\footnotetext{
5 Predictably, the survey may slightly under-represent young individuals, and slightly over-estimate educated, national and (by construction) Italian-speaking people. When appropriate, we control for these variables with our econometric models. Our main findings are unchanged if using sampling weights. Given the extent of the rejection rate observed in the ballot, and in our data, we tested whether our main results may be affected when overweighting yes-votes. We find that our main results are in most cases quantitatively and otherwise qualitatively unchanged even when doubling the weight given to a yes-observation.
} 
Table 2 VOX data: main outcomes and determinants of voting

\begin{tabular}{lrrrrr}
\hline Variable & Mean & SD & Min. & Max. & \multicolumn{1}{c}{ N } \\
\hline Voting decision & & & & & \\
$\quad$ No-vote & 0.898 & 0.302 & 0 & 1 & 914 \\
$\quad$ Participation & 0.679 & 0.467 & 0 & 1 & 1509 \\
$\quad$ Opinion formation & -16.314 & 10.625 & -1 & -42 & 714 \\
$\quad$ Time of resolution before ballot day & 0.186 & 0.389 & 0 & 1 & 1514 \\
$\quad$ Immediate resolution & & & & & \\
Information & 2.767 & 0.861 & 1 & 4 & 1220 \\
$\quad$ Knowledge of the Energy Strategy 2050 & 0.661 & 0.473 & 0 & 1 & 1514 \\
$\quad$ Knowledge of the initiative & & & & & \\
Agreement with arguments in favor & 2.012 & 1.006 & 1 & 4 & 856 \\
$\quad$ Revenue neutrality & 2.652 & 1.079 & 1 & 4 & 922 \\
$\quad$ Environmental effectiveness & 2.364 & 1.040 & 1 & 4 & 857 \\
$\quad$ Energy security & & & & & \\
Agreement with arguments against & 3.026 & 1.004 & 1 & 4 & 908 \\
$\quad$ Competitiveness effects & 2.922 & 1.056 & 1 & 4 & 906 \\
$\quad$ Distributional effects & 3.002 & 1.012 & 1 & 4 & 852 \\
$\quad$ Decreasing tax base & & & & & \\
\hline
\end{tabular}

enue neutrality as a desirable property of the initiative did not receive much support, which corroborates the related stylized fact highlighted in the literature. The fact that higher fossil fuel prices would have resulted in a higher degree of independence from oil and gas exporters, and thus increased energy security, was moderately seen as a positive property of the energy tax. Among the pro arguments, the one that scores the highest relates with the effectiveness of energy taxes. The relative question asks respondents whether they believe that an energy tax creates incentives to save energy, and to switch to renewable energy. Yet, this straightforward question about the incentive effect of energy taxes does not receive massive support, and actually performs poorly overall. Once again, we observe how the effectiveness of energy taxes is not an established fact for the general public, and its ability to change behavior is not shared by all the population.

We first use the full sample to analyze the determinants of voting behavior, and participation in the ballot. We focus on the main results only. Since these two outcomes are jointly determined, we would face a selection problem if assessing voting behavior without taking into account the decision to participate or not in the ballot. We stress that participation is not compulsory in all cantons but one, the latter representing about $1 \%$ of the total population. We hence apply a standard Heckman selection strategy, and estimate jointly the probability to participate in the ballot, and to express either a "yes-" or a "no-vote". Since both outcomes are binary, we use a Heckman-selection probit model. The selection of variables follows from Thalmann (2004), who used comparable VOX data. We start with a reduced model including only "objective" socio-economic characteristics potentially affecting the decision to participate in the ballot, or to accept the initiative. We include gender, dummies for age categories, education, the number of cars in household (as a proxy for carbon footprint), and the location of the voter, in terms of linguistic region and with respect to the urban-rural cleavage. The procedure suggested in Thalmann (2004) implies running a second model, in 
which additional "subjective" variables are added to the "objective" model. From the standard questions of the VOX survey, we indeed know some general preferences, political priorities and concerns of the voters in our sample, as reported by respondents. In line with Thalmann (2004), we consider as potentially relevant for this ballot the following variables: concern with unemployment, with income inequality, and with public intervention in the economy. We also include a variable capturing the political affinity as declared by the respondents, based on the stated political positioning at the last national elections. Given that only two parties supported the popular initiative, the Green Liberals, its promoters, and the Green Party, while all others strongly opposed it, including all leftist parties, we capture support for either one of the two parties as a measure of affinity with green parties (called "green affinity" hereafter).

\subsubsection{Participation}

The top panel of Table 3 presents the estimates for the "objective" model. All coefficients are statistically significant in the participation model. Most estimates carry the expected sign: both higher education and age are correlated with a higher likelihood to participate in a ballot. Participation rates are higher for male individuals and in German speaking areas compared to French (the dummy of reference) and Italian speaking areas. Rural areas also experience higher turnout. These differences are very similar to those found by Thalmann (2004), and mirror general voting behavior in Switzerland. Interestingly, car ownership is also associated with higher ballot participation.

The bottom panel of Table 3 introduces the subjective variables. Most of the previous results concerning participation are robust to the addition of general political concerns and affinity. Among the subjective variables, only concern with unemployment is significantly linked to participation, with a positive sign as expected. The positive but non-significant effect for green affinity suggests that the sponsors and supporters of the initiative were not really able to mobilize their voters to participate in the ballot.

\subsubsection{Voting Behavior}

Taking into account self-selection into voting, the vote model assesses the effect of the previous variables on the likelihood to express a yes-vote in the ballot. We start again from the top panel of Table 3. Higher education is found to be positively correlated with pro-environmental behavior, as already shown by Deacon and Shapiro (1975). Females, young generations and older individuals are less likely to support the initiative, exactly as in Thalmann (2004).

The subjective variables seem to substantially contribute to explain variation in the model. In particular, we note how green affinity is linked to a higher propensity to support the initiative of the Green Liberals. Green voters may have intrinsically supported the initiative, or voted strategically for it in order to avoid a major defeat. Polls were indeed forecasting a rejection as the most probable outcome, even though the ultimate debacle was clearly unexpected. In line with predictions, concern with income inequality, with public intervention, and with unemployment are associated with a negative coefficient, although the last is not statistically significant. That is, the subjective variables seem to capture the main risks of the proposal. 
Table 3 Heckman-selection probit model

\begin{tabular}{|c|c|c|c|c|c|c|}
\hline & \multicolumn{4}{|l|}{ Vote model } & \multicolumn{2}{|c|}{ Participation model } \\
\hline & Coefficients & $(\mathrm{SE})$ & Marginal effects & $(\mathrm{SE})$ & Coefficients & $(\mathrm{SE})$ \\
\hline \multicolumn{7}{|l|}{ Objective model } \\
\hline Gender $(1=F)$ & $-0.250 * *$ & $(0.107)$ & $-0.029 * *$ & $(0.012)$ & $-0.138 *$ & $(0.074)$ \\
\hline Young ( $1=18-29$ years $)$ & $-0.642 * * *$ & $(0.224)$ & $-0.074 * * *$ & $(0.025)$ & $-0.940 * * *$ & $(0.118)$ \\
\hline Elderly $(1=60+$ years $)$ & $-0.180^{*}$ & $(0.119)$ & $-0.021 *$ & $(0.013)$ & $0.678 * * *$ & $(0.086)$ \\
\hline German speaking & 0.204 & $(0.126)$ & 0.023 & $(0.014)$ & $0.280 * *$ & $(0.086)$ \\
\hline Italian speaking & -0.145 & $(0.190)$ & -0.017 & $(0.022)$ & $-0.540 * * *$ & $(0.107)$ \\
\hline Education (1 = high school+) & $0.274 * *$ & $(0.116)$ & $0.032 * *$ & $(0.013)$ & $0.277 * * *$ & $(0.077)$ \\
\hline Number of cars in household & -0.084 & $(0.097)$ & -0.010 & $(0.011)$ & $0.140 * *$ & $(0.041)$ \\
\hline Municipality is rural & -0.098 & $(0.129)$ & -0.011 & $(0.015)$ & $0.271 * *$ & $(0.089)$ \\
\hline Intercept & $-1.418 * *$ & $(0.193)$ & & & -0.010 & $(0.120)$ \\
\hline$N$ & 1403 & & & & & \\
\hline Censored observations & 489 & & & & & \\
\hline Uncensored observations & 914 & & & & & \\
\hline \multicolumn{7}{|l|}{ Full model } \\
\hline Gender $(1=F)$ & $-0.240 * *$ & $(0.119)$ & $-0.024 * *$ & $(0.012)$ & -0.123 & $(0.078)$ \\
\hline Young $(1=18-29$ years $)$ & $-0.561 *$ & $(0.277)$ & $-0.056^{* *}$ & $(0.026)$ & $-0.936 * * *$ & $(0.120)$ \\
\hline Elderly ( $1=60+$ years $)$ & -0.044 & $(0.129)$ & -0.004 & $(0.013)$ & $0.671 * *$ & $(0.089)$ \\
\hline German speaking & 0.140 & $(0.137)$ & 0.004 & $(0.014)$ & $0.265 * * *$ & $(0.090)$ \\
\hline Italian speaking & 0.092 & $(0.204)$ & -0.009 & $(0.020)$ & $-0.605 * * *$ & $(0.090)$ \\
\hline Education (1 = high school+) & 0.145 & $(0.127)$ & 0.015 & $(0.013)$ & $0.268 * * *$ & $(0.079)$ \\
\hline Number of cars in household & -0.003 & $(0.083)$ & -0.0003 & $(0.008)$ & $0.113 * * *$ & $(0.042)$ \\
\hline Municipality is rural & 0.018 & $(0.138)$ & 0.002 & $(0.014)$ & $0.291 * * *$ & $(0.091)$ \\
\hline Concern with unemployment & -0.063 & $(0.046)$ & -0.006 & $(0.005)$ & $0.060 * *$ & $(0.027)$ \\
\hline Concern with income inequality & $-0.103 * * *$ & $(0.038)$ & $-0.010 * * *$ & $(0.004)$ & 0.022 & $(0.024)$ \\
\hline Concern with public intervention & $-0.068^{*}$ & $(0.037)$ & $-0.007^{*}$ & $(0.004)$ & -0.015 & $(0.023)$ \\
\hline Green affinity & $1.168 * * *$ & $(0.177)$ & $0.117 * * *$ & $(0.022)$ & 0.068 & $(0.159)$ \\
\hline Intercept & -0.557 & $(0.338)$ & & & $-0.378^{*}$ & $(0.221)$ \\
\hline$N$ & 1318 & & & & & \\
\hline Censored observations & 455 & & & & & \\
\hline Uncensored observations & 863 & & & & & \\
\hline
\end{tabular}

Robust standard errors in parentheses $* p<0.1 ; * * p<0.05$; *** $p<0.01$

\subsubsection{Voting Behavior, Including Pro and Con Arguments}

Table 4 shows the estimates for a model that includes the pros and cons described in Table 2. We recall that these variables are observed only for the respondents declaring to have participated in the ballot. Hence, we run a simple probit model, skipping the participation stage. Outcomes of interest are compared with the estimates of Table 3.

People's opinions on the pro and con arguments mentioned by the survey are the main drivers of voting behavior. All variables have the expected sign, and comparable magnitudes. 
Table 4 Probit model including pros and cons

\begin{tabular}{lllll}
\hline & Coefficient & (SE) & Marginal effects & (SE) \\
\hline Gender (1=F) & -0.311 & $(0.203)$ & -0.011 & $(0.008)$ \\
Young $(1=18-29$ years $)$ & -0.478 & $(0.427)$ & -0.017 & $(0.016)$ \\
Elderly (1=60+years) & -0.301 & $(0.207)$ & -0.011 & $(0.009)$ \\
German speaking & 0.256 & $(0.278)$ & 0.009 & $(0.010)$ \\
Italian speaking & 0.080 & $(0.360)$ & 0.003 & $(0.013)$ \\
Education (1=high school+) & -0.130 & $(0.217)$ & -0.005 & $(0.008)$ \\
Number of cars in household & $-0.457^{* *}$ & $(0.132)$ & $-0.016^{* *}$ & $(0.007)$ \\
Rural municipality & -0.051 & $(0.228)$ & -0.002 & $(0.008)$ \\
Concern with unemployment & -0.042 & $(0.079)$ & -0.002 & $(0.003)$ \\
Concern with income inequality & 0.019 & $(0.065)$ & 0.0006 & $(0.002)$ \\
Concern with public intervention & $-0.085^{*}$ & $(0.059)$ & $-0.003^{*}$ & $(0.002)$ \\
Green affinity & $0.628^{* *}$ & $(0.260)$ & $0.022^{* *}$ & $(0.011)$ \\
Revenue neutrality & $0.617^{* * *}$ & $(0.103)$ & $0.022^{* *}$ & $(0.007)$ \\
Environmental effectiveness & $0.378^{* * *}$ & $(0.110)$ & $0.013^{* *}$ & $(0.005)$ \\
Energy security & $0.181^{*}$ & $(0.108)$ & $0.007^{*}$ & $(0.004)$ \\
Competitiveness effects & $-0.394^{* *}$ & $(0.094)$ & $-0.014^{* *}$ & $(0.005)$ \\
Regressive effects & $-0.165^{*}$ & $(0.089)$ & $-0.006^{*}$ & $(0.003)$ \\
Decreasing tax base & -0.057 & $(0.099)$ & -0.002 & $(0.003)$ \\
Intercept & $-1.567^{*}$ & $(0.848)$ & & \\
$N$ & 607 & & & \\
Pseudo $R^{2}$ & 0.503 & & & \\
\hline Robust sta & & & &
\end{tabular}

Robust standard errors in parentheses

$* p<0.1 ; * * p<0.05 ; * * p<0.01$

Only the coefficient for the argument about a decreasing tax base is too small to be statistically significant. The adverse consequences of a decreasing tax base may already be accounted for by the other variables. When looking at the marginal effects for these arguments, we observe that the Green Liberals' popular initiative was rejected based on the very same contrary arguments that are most often mentioned in the literature. Similarly, the pro arguments contributed to higher acceptability, but their lower uptake among the general public, again in line with the literature, did not help to substantially move the balance in favor of the reform.

For instance, the higher the agreement with the statement considering revenue neutrality as a positive aspect of the proposed reform, the higher the likelihood of having voted yes. Yet, on average people were not particularly interested in revenue neutrality. The same applies to the energy security argument. A recurrent finding concerning the perception of environmental effectiveness, largely discussed in the introductory part, is corroborated by our ballot data. Being relatively confident that energy taxes provide an incentive to decrease energy consumption and to switch to cleaner sources is linked with a higher probability of a yes-vote. The magnitude of this effect may look relatively small if we compare with other survey studies testing the effect of perceived effectiveness on acceptability in a similar fashion, such as Baranzini and Carattini (2017). However, assessing the relevance of this and the other effects should take into account the overall outcome of the ballot, very well replicated by the VOX survey. In this light, the effects that we measure are considerable. 
Similar considerations apply to the contrary arguments. The only difference is that these were on average considered much more relevant than the pro arguments. Competitiveness effects were already determinant in the ballot analyzed by Thalmann (2004), in spite of an unemployment level below $2 \%$ at that time in Switzerland. At the time of the ballot that we analyze, the unemployment rate was comfortably below $4 \%$. Similarly to other contexts, competitiveness concerns often take the center stage when it comes to take important political decisions on climate policy. This can happen in spite of the overall minimal adverse effects on competitiveness observed so far (cf. e.g. Mathys and Melo 2011). For instance, when designing their carbon taxes, Scandinavian countries opted for very generous exemptions to energy-intensive industries on competitiveness grounds, avoiding important profit losses to the firms concerned, but also watering down the environmental effects of the policy (Baranzini and Carattini 2014). The industry-flight argument and related fears of substantial competitiveness effects largely contributed to the policy reversal observed in the case of the Australian carbon tax (cf. Spash and Lo 2012). Hence, the general public may tend to overestimate competitiveness effects, and this may be the result of very effective political campaigning by energy-intensive industries and fossil energy providers (cf. Ingold and Varone 2012).

Among the objective variables, only one significantly explains voting behavior once taking into account subjective variables and opinions on the popular initiative. This variable is the number of cars in the households, which now reaches statistical significance. That is, as in Thalmann (2004), the number of cars could be a measure of people's economic sensitivity to higher energy prices, as families with more cars are less likely to approve the initiative. Concerning subjective variables, the concern for public intervention remains significant, and its magnitude virtually unchanged with respect to Table 3. Green affinity keeps its significance, although the marginal effect is reduced.

\subsubsection{Alternative Recycling Schemes}

We complete the analysis by testing the potential popularity of alternative recycling schemes. Two specific questions were added to the standard VOX questionnaire, asking for the preferred recycling option, freely, first, and then among a list of four options. These options are: subsidies for energy efficiency improvements and renewable energy (environmental earmarking), social cushioning, reduction in existing taxes, and redistribution to households and firms. Most answers given in the open question correspond to one of these four categories. That is, the results of the open question, in which respondents are not influenced by the options given by the questionnaire, are very similar to those of the closed question, displayed in Table 5.

Unsurprisingly, about $60 \%$ of respondents would like the revenues from energy taxes to be used in the environmental domain. This result confirms previous findings in the literature,

Table 5 Preferred modes of recycling

\begin{tabular}{lllll}
\hline Variable & Mean & SD & Min. & Max. \\
\hline Subsidies for efficiency and renewables & 0.568 & 0.496 & 0 & 1 \\
Social cushioning & 0.115 & 0.320 & 0 & 1 \\
Reduction in existing taxes & 0.13 & 0.337 & 0 & 1 \\
Redistribution to households and firms & 0.186 & 0.389 & 0 & 1 \\
\hline
\end{tabular}


and suggests that Swiss voters are not different from the other samples analyzed so far. Only a small fraction of the population would use tax revenues to provide social cushioning, or to reduce existing taxes, and that in spite of the concerns expressed for distributional and competitiveness effects. Similar findings on this apparent inconsistency were already provided by Baranzini and Carattini (2017), based on a specific Swiss canton. Apparently, such concerns affect the decision to accept or not an energy tax at a given tax rate, but do not call for a diversion of revenues from environmental earmarking. Redistribution to households and firms, the current way of redistributing revenues from the existing Swiss carbon tax on heating and process fuels, is supported by about one fifth of the sample only. That is, if citizens were asked to vote on the use of revenues of the current scheme, absent any additional information they would probably reject lump-sum transfers, and favor a switch towards full earmarking of revenues. ${ }^{6}$

\subsection{Choice Experiment on Alternative Carbon Tax Designs}

In this section we analyze decision making in our full-information choice-experiment setting and compare it with the observed real voting behavior, and with the previous literature, with the aim of testing our two main hypotheses concerning tax rates and recycling modes. Table 6 presents our main estimates. All columns display marginal effects from conditional logit. Column (1) shows estimates for the full sample, i.e. 1189 individuals. Since we survey a representative sample of the population living in Switzerland, not all respondents are Swiss nationals and so entitled to vote. Hence, column (2) restricts the sample to nationals only. Among nationals, we have a self-declared measure of participation in the usual four ballots per year. Column (3) excludes non-voters while column (4) retains only people declaring to participate in all ballots. Since all results remain the same in qualitative terms and most of the time also in quantitative terms, we discuss the coefficients based on column (1). The fact that we find similar results for different sub-samples is however an interesting finding in itself. That is, foreign respondents would not vote differently than Swiss citizens, according to this sample and for this matter. If we exclude those individuals that are most likely to abstain to better predict the outcome of a potential ballot, the results are also virtually unchanged. The propensity to vote seems thus to have no influence on how people perceive the tax designs proposed in our study, in spite of the non-negligible changes in samples across columns.

As expected, a higher tax rate is linked to a lower acceptability, everything else equal. This is a standard public choice result, in line with Sælen and Kallbekken (2011), Brannlund and Persson (2012) and Gevrek and Uyduranoglu (2015). However, the difference in acceptance between 0 and 60 francs is relatively small in comparison with the other tax rates. Hence, in some situations, people might prefer a small carbon tax than no carbon tax at all. Given that the tax rate of the current Swiss carbon tax on heating and process fuels was already fixed at 60 francs at the time of the survey, we did not include in the survey a lower tax rate, e.g. of 30 francs. Furthermore, we note that except for the first step from 0 to 60 francs, the progression is almost linear, suggesting that a well-shaped linear demand would be a good approximation for the case of carbon taxes.

This linearity allows speculating on the negative impact on acceptability of an extremely high rate, as the one suggested by the popular initiative promoted by the Green Liberals and rejected by the Swiss population. While promoters of and opponents to the popular initiative were disagreeing on the proposal's expected impact on energy prices, depending on the time horizon that they used in their campaign, our most conservative computations suggest that

6 Note that up to one third of revenues are already earmarked for subsidies for energy efficiency in buildings. 
Table 6 Choice experiment: estimates from conditional logit

\begin{tabular}{lllll}
\hline & $\begin{array}{l}\text { Full sample } \\
(1)\end{array}$ & $\begin{array}{l}\text { Nationals } \\
(2)\end{array}$ & $\begin{array}{l}\text { Without no-voters } \\
(3)\end{array}$ & $\begin{array}{l}\text { Always voters } \\
(4)\end{array}$ \\
\hline Tax rate & & & & \\
0 CHF (reference) & & & & \\
$60 \mathrm{CHF}$ & -0.018 & -0.030 & $-0.037^{* *}$ & $-0.043^{*}$ \\
& $(0.015)$ & $(0.016)$ & $(0.067)$ & $(0.020)$ \\
90CHF & $-0.052^{* * * *}$ & $-0.059^{* * *}$ & $-0.065^{* * *}$ & $-0.070^{* * *}$ \\
& $(0.015)$ & $(0.016)$ & $(0.017)$ & $(0.021)$ \\
120CHF & $-0.107^{* * *}$ & $-0.122^{* * *}$ & $-0.123^{* * *}$ & $-0.122^{* * *}$ \\
& $(0.015)$ & $(0.016)$ & $(0.017)$ & $(0.020)$ \\
150CHF & $-0.177^{* * *}$ & $-0.186^{* * *}$ & $-0.193^{* * *}$ & $-0.200^{* * *}$ \\
& $(0.018)$ & $(0.016)$ & $(0.017)$ & $(0.02)$ \\
Revenue recycling & & & & \\
Income tax rebate (reference) & & & & -0.016 \\
VAT reduction & -0.013 & -0.010 & -0.012 & $(0.016)$ \\
& $(0.011)$ & $(0.012)$ & $(0.013)$ & $0.127^{* * *}$ \\
Lump-sum redistribution & $0.137^{* * *}$ & $0.136^{* * *}$ & $0.135^{* * *}$ & $(0.016)$ \\
& $(0.012)$ & $(0.012)$ & $(0.013)$ & $0.135^{* * *}$ \\
Social cushioning & $0.144^{* * * *}$ & $0.145^{* * *}$ & $0.144^{* * * *}$ & $(0.016)$ \\
Environmental recycling & $(0.011)$ & $(0.012)$ & $(0.012)$ & $-0.056^{* *}$ \\
Number of individuals & -0.021 & $-0.029^{*}$ & $-0.035^{* *}$ & $(0.018)$ \\
Number of hypothetical votes & $(0.013)$ & $(0.014)$ & $(0.014)$ & 650 \\
Pseudo- $R^{2}$ & 1189 & 1066 & 980 & 15600 \\
\hline & 28536 & 25584 & 23520 & 0.0404 \\
\hline
\end{tabular}

Estimates report marginal effects from conditional logit

The dependent variable measures the acceptability of the proposed carbon tax designs

Robust standard error in parentheses

$* p<0.1 ; * * p<0.05 ; * * * p<0.01$

in the short term the tax rate would have had to be of at least $300 \mathrm{CHF} / \mathrm{tCO}_{2}$ to fully replace the revenues of the VAT. Figure 1 extrapolates linearly from the probabilities of success that we observe based on the tax rates proposed by the survey and predicts the outcome of an initiative proposing a tax rate of $300 \mathrm{CHF} / \mathrm{tCO}_{2}$ (see Table 10 for descriptive statistics). For a like-to-like comparison, Fig. 1 shows only the predicted likelihood of success if revenues were to be used as proposed by the Green Liberals. While interpreting any out-of-sample prediction always requires a lot of precaution, our extrapolation provides support for the external validity of our choice experiment. At a rate of $300 \mathrm{CHF} / \mathrm{tCO}_{2}$ the predicted support is virtually zero, which is very close to the share of yes-votes in the public ballot. That is, if anything, our choice experiment predicts lower support than the ballot.

The Green Liberals' popular initiative could probably have had a better outcome with a different use of tax revenues. As the estimates show, reducing the current value-added tax does not raise acceptability relative to income tax rebates (the reference case, omitted due to multicollinearity). Together, these two revenue-recycling options are the most unpopular. This result comes as expected and confirms our hypothesis on the low support for the idea 


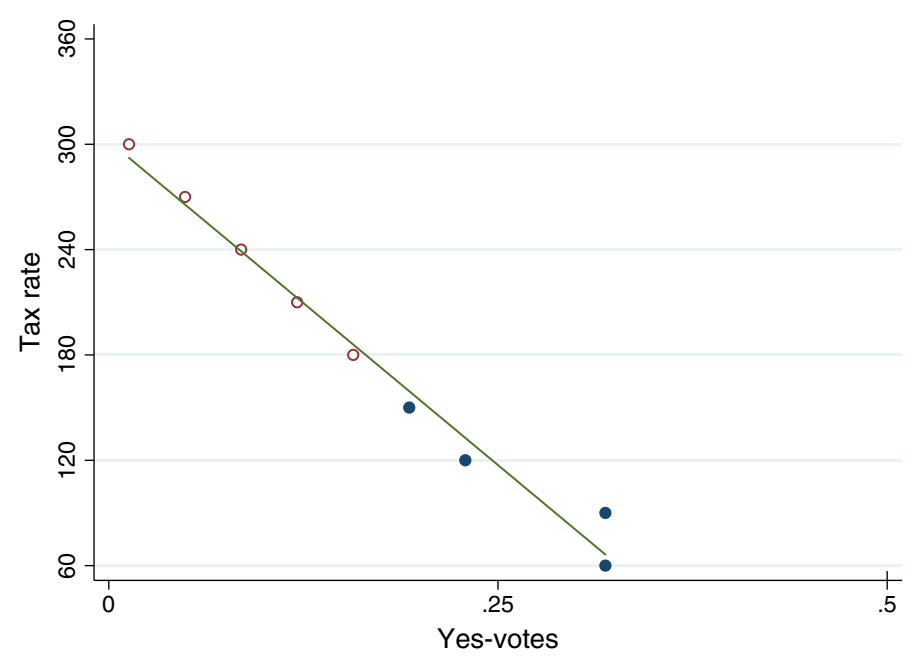

Fig. 1 Prediction with VAT recycling as in the Green Liberals' initiative. Note: Filled circles indicate observations in the sample, empty circles indicate observations obtained through extrapolation

of introducing new taxes to reduce others. In this respect, it is important to recall that based on the modeling exercise we find none or little double dividend with these two ways to recycle revenues, the net effect on the domestic purchasing power being broadly as negative as with the other types of recycling. This confirms a general result in the double-dividend literature (Goulder 1995). Hence, respondents informed about the potential beneficial effects of reducing distortionary taxes knew that they should not be expecting much of a double dividend from lower income taxes or a reduction in the value-added tax.

We are however surprised by the estimates concerning lump-sum transfers, environmental earmarking and to some extent social cushioning. The results that we provide for these variables are novel in the literature and deserve to be analyzed carefully. The signs for these variables are positive, negative and positive, respectively. That is, we find that lumpsum transfers and social cushioning are the most preferred options for recycling, while environmental recycling does not seem to obtain the support that it usually receives in the literature. We have an explanation for these results and we derive salient policy implications from them.

The most important finding concerns the low demand for recycling for environmental purposes. This result is at odds with most of the literature on the acceptability of environmental taxes previously discussed. This is the first study providing survey respondents with an estimate of the emission abatements linked with the carbon taxes on which respondents are requested to express their opinion. Interviewers were instructed on how to provide simple explanations on the price sensitivity of consumers and they reportedly had to use such information to answer the general public's curiosity on the economic bases for the figures for emissions abatements included in the choice cards. That is, our survey addressed by construction one of the main obstacles to carbon taxes: perceived ineffectiveness, which often goes hand in hand with the demand for environmental earmarking. Since all carbon taxes in the survey are shown to be effective, and to the extent that the scientific credibility of our study was not challenged by respondents, the main driver for the demand for environmental recycling is wiped out. 
We also note that the demand for environmental recycling expressed so often in the literature may not necessarily correspond to the most effective way of obtaining additional emission abatements as economists would interpret it. Even with a conservative estimate for the price of emissions on foreign carbon markets, the revenues of a carbon tax between 60 and 150 francs per ton of $\mathrm{CO}_{2}$ can lead to very large emission abatements abroad. All scenarios imply substantial negative emissions: even the lowest tax rate is shown to lead to abatements equivalent to five times Swiss emissions. Therefore, at the current carbon price levels, it would be very tempting for policy-makers to purchase many years of carbon neutrality and so achieve long-term pledges, such as "the balance" between emissions and removals by sinks, at an extremely low cost. However, we understand that the respondents in our survey may wonder why compensating so much. The general public may also do not like the purchase of foreign carbon credits more in general. People may have a preference for local investments, which provide a number of local co-benefits, and may also have ethical or practical reservations with respect to the use of offsets in general (see Conte and Kotchen 2010; Anderson 2012; Carattini and Tavoni 2016).

We now discuss the relatively high acceptability of the lump-sum redistribution. The modeling exercise suggests moderate net gains for low-income households with lump-sum transfers. Only social cushioning does better, while the remaining types of recycling involve regressive effects. Respondents are informed about this fact and can internalize the beneficial distributional properties of lump-sum redistribution. Furthermore, respondents are informed by the introductory material that the current carbon tax on heating and process fuels is mostly redistributed through lump-sum transfers and it may be that this information could have increased the legitimacy of this type of recycling. This information is public, but according to Baranzini and Carattini (2017), only a limited number of individuals are aware of the current carbon tax on heating and process fuels, and an even smaller proportion may know how its revenues are redistributed (e.g. one fourth of the 1012 respondents interviewed in INFRAS 2015).

Finally, the relative popularity of social cushioning does not completely surprise, given that distributional effects were made completely salient to respondents. Social cushioning is shown to provide the most progressive effects over all types of recycling, although lump-sum transfers perform similarly with moderate tax rates.

Figure 2 extends the simulation of Fig. 1 with the most popular recycling options, lumpsum recycling and social cushioning. As Fig. 1 already showed, our exercise suggests that even with an extremely low tax rate recycling through VAT rebates could hardly provide a majority in favor of a carbon tax. With social cushioning, and especially lump-sum transfers, the picture is different. While none of the two recycling options lead us to a majority with the tax rates considered by our survey, the prediction for recycling through lump-sum transfers suggests that anything below $60 \mathrm{CHF} / \mathrm{tCO}_{2}$ would be in principle acceptable. This was the rate of the Swiss carbon tax at the time of the vote (since 2016 it is at $84 \mathrm{CHF}$ ). While we recall the necessary precautions in taking at face values such predictions, we stress how recycling modes can completely shift the demand for carbon taxes, possibly also beyond the required threshold to make them acceptable. Based on these findings, we reformulate hypothesis 2 as follows:

Hypothesis 2 Revenue recycling We expect acceptability to vary substantially depending on the use of fiscal revenues. In relative terms, we expect lower acceptability with recycling through tax rebates and reductions, as taxing here and reducing taxes elsewhere is shown to be a criterion that the taxpayers probably generally do not request, or understand. This is particularly true in the absence 


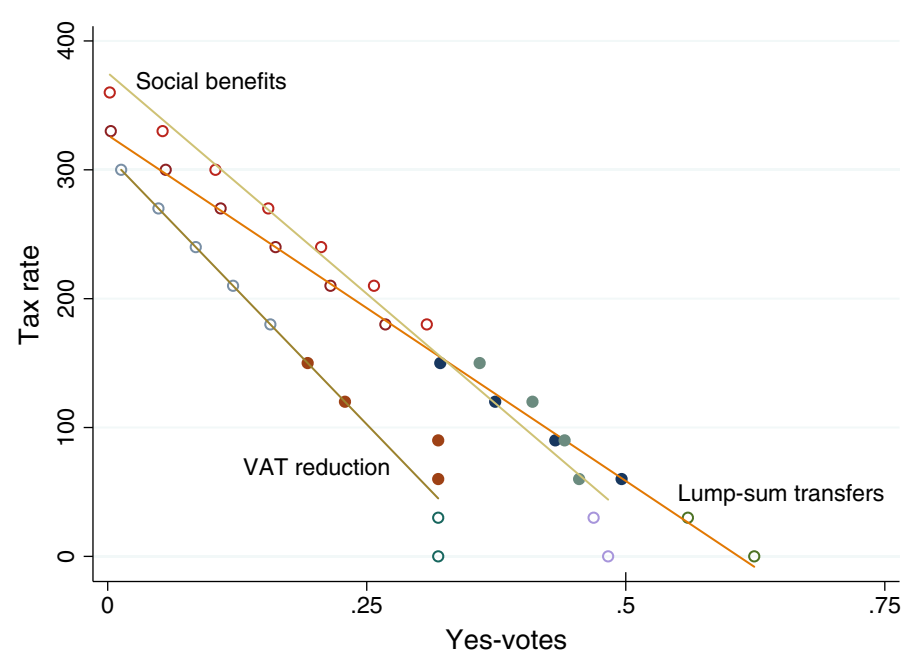

Fig. 2 Prediction with alternative recycling compared to VAT recycling. Note: Filled circles indicate observations in the sample, empty circles indicate observations obtained through extrapolation

of a substantial double dividend. Lump-sum redistribution can be associated to higher acceptability provided that its progressive properties are made explicit. If distributional effects are salient, social cushioning and lump-sum redistribution can lead to higher acceptability. Providing information on carbon emissions abatements reduces the usual demand for revenue recycling for environmental reinforcement, as it shows to voters the effectiveness of the carbon tax, which they may believe to be small absent any figure. Some types of environmental recycling may even cause lower support, such as recycling through the purchase of foreign carbon credits.

Finally, we consider how exploiting heterogeneity across individuals may provide further information on people's preferences for carbon taxes. Similarly to e.g. Gevrek and Uyduranoglu (2015), we apply a latent-class model to explain heterogeneous preferences. According to our data, 5 latent classes can be identified. ${ }^{7}$ Table 11 in the "Appendix" displays how preferences change across classes, based again on a conditional logit model. Table 12 introduces information on the characteristics of respondents, aiming at describing the composition of classes using a multinomial logit model. ${ }^{8}$

We briefly summarize the insights from this additional analysis. Classes are divided based on the importance given to each attribute (price or revenue recycling), on the preference for revenue recycling, the elasticity to variation in the tax rate, and overall acceptability. Low-income households tend to be associated with classes showing a marked preference for progressive designs, i.e. with lump-sum redistribution of revenues or social cushioning. The overall degree of acceptability, and the related sensitivity to tax rates, seems to be linked to different degrees of climate concern. Classes with lower degrees of climate concern tend to be linked to rather elastic behavior, and low to moderate overall acceptability. While a positive

7 AIC (BIC) values are given as follows: for two classes, 15,495 (15,616); for three classes, 14,835 (15,021); for four classes, 14,620 (14,870); for five classes, 14,427 (14,741).

8 The number of observations is limited for a series of variables, such as income or commuting preferences for workers. 
correlation between concern for climate mitigation and preferences for tighter climate policy is common in the literature (see Drews and van den Bergh 2016), we are, to the best of our knowledge, the first to empirically document different preferences for the distributional effects of carbon taxes across the income distribution.

\subsection{Discussion}

\subsubsection{Tax Rate}

We find that higher tax rates clearly imply lower acceptability. This fact recalls once again the general public's sensibility with respect to the cost of climate policy, above all when the latter is as transparent as with carbon taxes. As pointed out in the literature, this reminds policy-makers of the importance of proceeding in small steps (Baranzini and Carattini 2014). ${ }^{9}$ Starting at a moderate tax level may also reduce the opposition by energy-intensive lobbies, even though some evidence suggests that vested interests may be mobilized against any departure from the status quo (see e.g. Rocchi et al. 2014). In this respect, it is important that policy-makers have at their disposal estimates of the potential competitiveness effects of carbon taxes. These are indeed likely to be small overall and should not be overemphasized. Our results suggest that the general public is likely to be ready to give up some fraction of national income, if it is convinced on the environmental effectiveness of the measures. Hence, resistance to carbon taxes seems not to be due to complete free riding in the provision of the global public good represented by climate change mitigation, thus supporting the idea of some degree of cooperation in the climate commons (cf. Ostrom 2009; Carattini et al. 2015, 2017).

\subsubsection{Gradual Introduction and Information}

The acceptability for a given instrument may increase once the instrument is in place, supporting the use of moderate tax rates to start. This for three reasons. First, the role of relative consumption: once the tax is in place, people realize that their purchasing power compared to others around them may be actually unchanged (Howarth 2006; Gowdy 2008). Second, the role of revenue recycling: revenue neutrality can increase acceptability ex post, once people see that they are given some of the money back. Of course, this requires the redistribution of revenues to be sufficiently salient. For instance, the Citizens' Climate Lobby suggests introducing a carbon tax in the United States with lump-sum redistribution of revenues, and markets it as a "carbon fee and dividend". Every household would receive a yearly check, a dividend in the same spirit of the very popular Alaska Permanent Fund. With full redistribution, many households are net winners, as with feebates. Third, the role of observing the functioning of the policy: as discussed, the general public tends to underestimate the effectiveness of environmental taxes, especially absent any recycling for environmental purposes. However, if the effect of the policy is sufficiently salient, people may review their beliefs ex post, causing an important gap between perceived effectiveness (and thus acceptability) ex ante and ex post. Evidence in this sense is provided for instance by Carattini et al. (2016), who exploit the forced implementation of pricing garbage by the bag on a relatively large population to assess its overall effectiveness, and its acceptability both before and after the implementation. People are very concerned with pricing ex ante, but implementing the policy substantially reduces concerns with effectiveness and fairness. Similarly, Kallbekken and

\footnotetext{
9 The descriptive statistics in Table 8 report that a substantial majority of the choice-experiment sample would have a preference for a carbon tax that starts low and increases over time.
} 
Sælen (2011) have argued in favor of the use of trial periods, based on the successful example of the Stockholm congestion charge (see also Cherry et al. 2014). In the specific case of carbon taxes, Murray and Rivers (2015) show based on poll data how resistance against British Columbia's carbon tax substantially decreased after its introduction, with positive spillovers to the rest of Canada. In the case under consideration, we note that although Switzerland already has a carbon tax on heating and process fuels, an important fraction of the population is not aware of its existence (and thus of its redistribution policy). Our choice experiment was designed to inform voters on the effectiveness of the incentive tax using specific numbers, something that is often missing in similar studies in the literature as well as in the political arena.

\subsubsection{Revenue Recycling}

Selling an energy tax may be hard, but not impossible. Our findings from the choice experiment support the decision of the Swiss government to go for full lump-sum recycling in the planned extension of the current carbon tax on heating fuels to all fuels, as announced in March 2015. However, our specific framework provides more detailed information on the consequences of climate policy than is common in the public arena. As emphasized by the VOX survey, when asked how to recycle the revenues of a green tax, a majority of voters propose environmental earmarking. Only when informed about the effectiveness of the tax, as in the choice experiment, other modes of recycling become more acceptable, in particular lump-sum redistribution and social cushioning. These need not be better modes of recycling the revenues of an incentive tax, but nevertheless voters should be informed clearly and objectively about the effectiveness of an incentive tax, which is often hard to grasp for the general public. These figures could also emphasize the existence of co-benefits for the local population. Expecting positive co-benefits is indeed associated with higher willingness to pay for climate change mitigation (Longo et al. 2012) as well as higher acceptability of carbon taxes (Baranzini and Carattini 2017). The general public should also be informed about the other effects of the tax, such as on competitiveness and the distribution of burdens. In particular, people do not generally see the redistributive nature of lump-sum transfers. That is, the general public should be informed about the drawbacks and advantages of the proposed mode of revenue recycling.

We are aware that who provides this information, and how it is framed, may matter for the public opinion, in particular for some specific subgroups. While testing this effect is beyond the scope of this paper, we refer to a large body of work having analyzed the role of "cues" and "frames" in different policy areas (cf. e.g. Zaller 1992; Chong and Druckman 2011). A cue is a piece of information that voters use to decide on complex issues (Eagly and Chaiken 1993). It allows voters to save time and avoid learning the details about the policy issue at stake. Typically, citizens who are close to a political party will follow its vote recommendation, without necessarily improving their knowledge about and reflecting on this issue (Lenz 2012). A frame puts the emphasis on a specific interpretation of a policy issue (Druckman and Nelson 2003). The literature has been testing, with mixed findings, whether and when cues and frames work (see e.g. Bullock 2011). In the case of climate change, framing that emphasizes certain outcomes, included in our analysis or beyond (as mentioned, local air quality, health outcomes), may help in increasing support for climate policy (see e.g. Lakoff 2010; Lockwood 2011; Bain et al. 2012, 2016; Myers et al. 2012). However, when opinions are particularly polarized, access to information may have counterproductive effects, depending on the opinion of the recipient (Kahan et al. 2011; Hart and Nisbet 2012). 


\section{Conclusions}

National pledges are not per se credible policy commitments. The ability of countries to back their pledges with cost-effective policies such as carbon taxes will determine the possibility to ramp up future ambitions and to push for further policy tightening. The implementation of carbon taxes has proven difficult in many countries, so far. Learning from these experiences is crucial to increase their popularity and broaden their implementation in a post-Paris world.

This paper analyzes voting behavior in a real ballot on an energy tax in Switzerland. Revenues from this energy tax were to replace completely the current value-added tax. The proposal was massively rejected. We collected data on a large representative sample of voters. We find that several obstacles limited its acceptability, such as distributional and competitiveness concerns and perceived environmental ineffectiveness. Given the perception of little environmental effects, revenue neutrality is not a priori a solution for the general public. This energy tax would have instead been more popular if revenues were to be earmarked for environmental purposes.

At the same time of the ballot, we administered a choice-experiment survey, exploiting the salience of the topic. The choice experiment addressed all the obstacles emphasized by the analysis of real voting behavior. Based on a computable general equilibrium model, it provided information to all respondents on the social, economic and environmental impacts for different tax rates and use of revenues. We analyze the demand for carbon taxes for each design and show that this information leads to a very different outcome compared to the ballot and the literature. First of all, revenue-neutral designs can become popular, provided that the redistribution is achieved in a progressive fashion and its distributional effects are explained to the public, as can be the case with lump-sum transfers. Second, environmental earmarking may no longer be absolutely necessary to receive a substantial support for carbon taxes, if information is provided on their environmental effectiveness.

Based on our findings we argue that policy designs usually preferred by economists, but in most cases opposed by the general public, are not necessarily unpopular, provided that the general public shares at least some of the information that economists have. Our findings can help devise effective carbon taxes that are accepted by citizens, because they are convincingly shown to be environmentally effective and because their revenues are refunded in a form that mitigates their burden on low-income households. Addressing the concerns and limited information of the general public is probably the only way to avoid important resistances to cost-effective instruments of climate change mitigation, which could put at risk the realization of the current pledges and potentially jeopardize their necessary tightening. The consequences are known. The inability to turn Paris pledges into policy would this time hardly leave any room to avoid running into dangerous climate changes.

Open Access This article is distributed under the terms of the Creative Commons Attribution 4.0 International License (http://creativecommons.org/licenses/by/4.0/), which permits unrestricted use, distribution, and reproduction in any medium, provided you give appropriate credit to the original author(s) and the source, provide a link to the Creative Commons license, and indicate if changes were made.

\section{Appendix}

See Fig. 3 and Tables 7, 8, 9, 10, 11 and 12. 
Fig. 3 Example of a choice card

\begin{tabular}{l} 
Tax rate: CHF 150 / ton of $\mathrm{CO}_{2}$ \\
Use of revenues: income tax rebates \\
\hline Order of magnitude of impacts: \\
- Increase in energy \\
prices (gasoline, \\
diesel, heating fuel) \\
- CO2 emissions \\
abatements in \\
Switzerland \\
Purchasing power of \\
all households \\
Purchasing power of \\
low-income \\
households
\end{tabular}

$\square$ VOTE

Table 7 VOX data: sample composition

\begin{tabular}{|c|c|c|c|c|c|}
\hline Variable & Mean & SD & Min. & Max. & $\mathrm{N}$ \\
\hline Gender (female) & 0.526 & 0.5 & 0 & 1 & 1514 \\
\hline Age 18-29 (young) & 0.117 & 0.321 & 0 & 1 & 1514 \\
\hline Age $30-59$ & 0.532 & 0.499 & 0 & 1 & 1514 \\
\hline Age 60+ (elderly) & 0.351 & 0.477 & 0 & 1 & 1514 \\
\hline German speaking & 0.534 & 0.499 & 0 & 1 & 1514 \\
\hline French speaking & 0.267 & 0.442 & 0 & 1 & 1514 \\
\hline Italian speaking & 0.199 & 0.399 & 0 & 1 & 1514 \\
\hline Education (high school+) & 0.616 & 0.486 & 0 & 1 & 1514 \\
\hline Number of cars in household & 1.381 & 1.031 & 0 & 9 & 1514 \\
\hline Rural municipality & 0.258 & 0.437 & 0 & 1 & 1514 \\
\hline Concern with unemployment & 4.846 & 1.487 & 1 & 6 & 1488 \\
\hline Concern with income inequality & 3.952 & 1.649 & 1 & 8 & 1489 \\
\hline Concern with public intervention & 4.249 & 1.668 & 1 & 6 & 1444 \\
\hline Green affinity & 0.063 & 0.243 & 0 & 1 & 1514 \\
\hline
\end{tabular}


Table 8 Choice experiment: sample composition

\begin{tabular}{|c|c|c|c|c|c|}
\hline Variable & Mean & $\mathrm{SD}$ & Min. & Max. & $\mathrm{N}$ \\
\hline \multicolumn{6}{|l|}{ Socio-economic characteristics } \\
\hline Gender (male) & 0.487 & 0.5 & 0 & 1 & 1200 \\
\hline Age & 51.711 & 15.263 & 18 & 94 & 1200 \\
\hline National & 0.897 & 0.305 & 0 & 1 & 1200 \\
\hline Education (years of) & 15.341 & 2.072 & 11 & 18 & 1196 \\
\hline Household size & 2.884 & 1.333 & 1 & 8 & 1200 \\
\hline \multicolumn{6}{|l|}{ Household annual income } \\
\hline$<35,000 \mathrm{CHF}$ & 0.06 & 0.237 & 0 & 1 & 957 \\
\hline $35,000-50,000 \mathrm{CHF}$ & 0.144 & 0.351 & 0 & 1 & 957 \\
\hline $50,000-80,000 \mathrm{CHF}$ & 0.242 & 0.429 & 0 & 1 & 957 \\
\hline $80,000-120,000 \mathrm{CHF}$ & 0.304 & 0.46 & 0 & 1 & 957 \\
\hline $120,000-160,000 \mathrm{CHF}$ & 0.154 & 0.361 & 0 & 1 & 957 \\
\hline $160,000-200,000 \mathrm{CHF}$ & 0.047 & 0.212 & 0 & 1 & 957 \\
\hline$>200,000 \mathrm{CHF}$ & 0.049 & 0.216 & 0 & 1 & 957 \\
\hline \multicolumn{6}{|l|}{ Geographical location } \\
\hline German speaking & 0.542 & 0.498 & 0 & 1 & 1200 \\
\hline French speaking & 0.292 & 0.455 & 0 & 1 & 1200 \\
\hline Italian speaking & 0.167 & 0.373 & 0 & 1 & 1200 \\
\hline Urban agglomeration & 0.264 & 0.441 & 0 & 1 & 1200 \\
\hline \multicolumn{6}{|l|}{ Environmental attitudes } \\
\hline \multicolumn{6}{|l|}{ Main transport for commuting } \\
\hline Car & 0.578 & 0.494 & 0 & 1 & 969 \\
\hline Bicycle & 0.195 & 0.396 & 0 & 1 & 969 \\
\hline Bus & 0.227 & 0.419 & 0 & 1 & 969 \\
\hline \multicolumn{6}{|l|}{ Concern for climate change } \\
\hline Very threatening & 0.405 & 0.491 & 0 & 1 & 1189 \\
\hline Somewhat threatening & 0.476 & 0.500 & 0 & 1 & 1189 \\
\hline Not threatening & 0.119 & 0.324 & 0 & 1 & 1189 \\
\hline Preference for gradual carbon tax & 0.635 & 0.482 & 0 & 1 & 1200 \\
\hline
\end{tabular}

Table 9 Swiss population: socio-economic characteristics for comparison. Source All variables come from Swiss Statistics and concern the end of 2014. Election data concern the federal elections of 2015

\begin{tabular}{ll}
\hline Variable & Mean \\
\hline Socio-economic characteristics & \\
Gender (female) & 0.505 \\
Age 18-29 (young) & 0.149 \\
Age 30-59 & 0.448 \\
Age 60+ (elderly) & 0.234 \\
National & 0.757 \\
Education (high school+) & 0.521 \\
Household size & 2.25 \\
\hline
\end{tabular}


Table 9 continued

\begin{tabular}{lc}
\hline Variable & Mean \\
\hline Geographical location & \\
German speaking & 0.633 \\
French speaking & 0.227 \\
Italian speaking & 0.081 \\
Rural municipality & 0.17 \\
Environmental attitudes & \\
Votes to the Green Party & 0.063 \\
Votes to the Green Liberal Party & 0.072 \\
\hline
\end{tabular}

Table 10 Choice experiment: descriptive statistics

\begin{tabular}{lllll}
\hline & \multicolumn{2}{l}{ Tax rate } & & \\
\cline { 2 - 5 } & $60 \mathrm{CHF}$ & $90 \mathrm{CHF}$ & $120 \mathrm{CHF}$ & $150 \mathrm{CHF}$ \\
\hline Recycling & & & & 0.175 \\
$\quad$ Income tax rebate & 0.352 & 0.317 & 0.273 & 0.193 \\
VAT reduction & 0.319 & 0.319 & 0.229 & 0.321 \\
Lump-sum redistribution & 0.496 & 0.432 & 0.374 & 0.359 \\
Social cushioning & 0.455 & 0.441 & 0.410 & 0.148 \\
Environmental recycling & 0.350 & 0.295 & 0.215 & \\
\hline
\end{tabular}


Table 11 Latent classes: estimates from conditional logit

\begin{tabular}{|c|c|c|c|c|c|}
\hline & \multicolumn{5}{|c|}{ Latent classes } \\
\hline & (1) & (2) & (3) & (4) & (5) \\
\hline \multicolumn{6}{|l|}{ Tax rate } \\
\hline \multicolumn{6}{|l|}{$0 \mathrm{CHF}$ (reference) } \\
\hline \multirow[t]{2}{*}{$60 \mathrm{CHF}$} & $-0.130 * * *$ & $0.326 * * *$ & $-0.314 * * *$ & $0.582 * * *$ & 0.0161 \\
\hline & $(0.032)$ & $(0.013)$ & $(0.028)$ & $(0.0110)$ & $(0.026)$ \\
\hline \multirow[t]{2}{*}{$90 \mathrm{CHF}$} & $-0.099 * *$ & $0.377 * * *$ & $-0.425 * * *$ & $0.432 * * *$ & $-0.167 * * *$ \\
\hline & $(0.032)$ & $(0.010)$ & $(0.036)$ & $(0.017)$ & $(0.025)$ \\
\hline \multirow[t]{2}{*}{$120 \mathrm{CHF}$} & $-0.069^{*}$ & $0.379 * * *$ & $-0.387 * * *$ & $0.266^{* * * *}$ & $-0.308 * * *$ \\
\hline & $(0.023)$ & $(0.011)$ & $(0.033)$ & $(0.019)$ & $(0.028)$ \\
\hline \multirow[t]{2}{*}{$150 \mathrm{CHF}$} & $-0.119 * * *$ & $0.373 * * *$ & $-0.372 * * *$ & $0.126^{* * *}$ & $-0.463 * * *$ \\
\hline & $(0.028)$ & $(0.011)$ & $(0.035)$ & $(0.025)$ & $(0.031)$ \\
\hline \multicolumn{6}{|l|}{ Revenue recycling } \\
\hline \multicolumn{6}{|l|}{ Income tax rebate (reference) } \\
\hline \multirow[t]{2}{*}{ VAT reduction } & -0.0004 & -0.009 & $-0.094^{*}$ & 0.038 & 0.002 \\
\hline & $(0.030)$ & $(0.008)$ & $(0.044)$ & $(0.021)$ & $(0.029)$ \\
\hline \multirow[t]{2}{*}{ Lump-sum redistribution } & $0.552 * * *$ & $0.034 * * *$ & -0.027 & $0.059 * *$ & $0.125 * * *$ \\
\hline & $(0.031)$ & $(0.008)$ & $(0.039)$ & $(0.022)$ & $(0.026)$ \\
\hline \multirow[t]{2}{*}{ Social cushioning } & $0.589 * * *$ & $0.051 * * *$ & 0.0095 & $0.054 *$ & $0.104 * * *$ \\
\hline & $(0.0302)$ & $(0.008)$ & $(0.034)$ & $(0.023)$ & $(0.031)$ \\
\hline \multirow[t]{2}{*}{ Environmental recycling } & -0.051 & $-0.018 *$ & -0.067 & 0.019 & 0.063 \\
\hline & $(0.038)$ & $(0.009)$ & $(0.042)$ & $(0.020)$ & $(0.033)$ \\
\hline$N$ & 3861 & 8190 & 6564 & 4191 & 5334 \\
\hline Pseudo- $R^{2}$ & 0.3752 & 0.3523 & 0.8726 & 0.5399 & 0.1635 \\
\hline
\end{tabular}

Estimates report marginal effects from conditional logit. The dependent variable measures the acceptability of the proposed carbon tax designs. Robust standard error in parentheses

$* p<0.1$; ** $p<0.05$; *** $p<0.01$ 
Table 12 Latent classes: membership estimates from multinomial logit

\begin{tabular}{|c|c|c|c|c|c|}
\hline & $\begin{array}{l}\text { (1) } \\
\text { Latent class } 1\end{array}$ & $\begin{array}{l}\text { (2) } \\
\text { Latent class } 2\end{array}$ & $\begin{array}{l}\text { (3) } \\
\text { Latent class } 3\end{array}$ & $\begin{array}{l}\text { (4) } \\
\text { Latent class } 4\end{array}$ & $\begin{array}{l}(5) \\
\text { Latent class } 5\end{array}$ \\
\hline \multicolumn{6}{|c|}{ Socio-economic characteristics } \\
\hline Gender (male) & $-0.025(0.025)$ & $0.058 *(0.035)$ & $0.021(0.031)$ & $-0.034(0.028)$ & $-0.020(0.028)$ \\
\hline Age & $0.0006(0.001)$ & $0.0004(0.001)$ & $-0.0008(0.001)$ & $-0.0001(0.001)$ & $-0.0001(0.002)$ \\
\hline National & $0.017(0.041)$ & $-0.011(0.053)$ & $0.008(0.049)$ & $0.0154(0.045)$ & $-0.030(0.040)$ \\
\hline $\begin{array}{l}\text { Education (years } \\
\text { of) }\end{array}$ & $-0.009(0.007)$ & $0.007(0.009)$ & $-0.002(0.009)$ & $0.0001(0.007)$ & $0.004(0.008)$ \\
\hline Household size & $-0.004(0.009)$ & $0.012(0.014)$ & $-0.002(0.012)$ & $-0.004(0.011)$ & $-0.002(0.011)$ \\
\hline \multicolumn{6}{|c|}{ Household annual income } \\
\hline$<35,000 \mathrm{CHF}$ & $-0.286^{* *}(0.125)$ & $0.297 * * *(0.112)$ & $-0.069(0.103)$ & $-0.014(0.097)$ & $0.072(0.099)$ \\
\hline $\begin{array}{c}35,000- \\
50,000 \mathrm{CHF}\end{array}$ & $-0.142 * *(0.068)$ & $0.184 *(0.096)$ & $-0.066(0.077)$ & $0.014(0.073)$ & $0.010(0.085)$ \\
\hline $\begin{array}{c}50,000- \\
80,000 \mathrm{CHF}\end{array}$ & $-0.061(0.057)$ & $0.135(0.087)$ & $-0.070(0.068)$ & $-0.022(0.065)$ & $0.018(0.075)$ \\
\hline $\begin{array}{c}80,000- \\
120,000 \mathrm{CHF}\end{array}$ & $-0.061(0.051)$ & $0.108(0.083)$ & $-0.119 *(0.064)$ & $-0.005(0.061)$ & $0.077(0.070)$ \\
\hline $\begin{array}{c}120,000- \\
160,000 \mathrm{CHF}\end{array}$ & $-0.031(0.055)$ & $0.099(0.087)$ & $-0.090(0.068)$ & $0.034(0.064)$ & $-0.013(0.076)$ \\
\hline $\begin{array}{c}160,000- \\
200,000 \mathrm{CHF} \\
>200,000 \mathrm{CHF}\end{array}$ & $-0.055(0.073)$ & $0.117(0.103)$ & $-0.105(0.088)$ & $-0.041(0.088)$ & $0.084(0.087)$ \\
\hline \multicolumn{6}{|c|}{ Geographical location } \\
\hline French speaking & $0.0332(0.027)$ & $-0.040(0.036)$ & $0.005(0.034)$ & $0.0005(0.030)$ & $0.001(0.032)$ \\
\hline Italian speaking & $0.062 *(0.036)$ & $-0.056(0.050)$ & $-0.056(0.051)$ & $-0.007(0.041)$ & $0.057(0.042)$ \\
\hline \multicolumn{6}{|c|}{ German speaking (reference) } \\
\hline $\begin{array}{l}\text { Urban } \\
\text { agglomeration }\end{array}$ & $0.002(0.027)$ & $0.032(0.038)$ & $-0.012(0.036)$ & $-0.021(0.0314)$ & $-0.002(0.031)$ \\
\hline \multicolumn{6}{|c|}{ Environmental attitudes } \\
\hline \multicolumn{6}{|c|}{ Main transport for commuting } \\
\hline Car & $-0.027(0.030)$ & $-0.089 * *(0.040)$ & $-0.006(0.038)$ & $0.077 * *(0.039)$ & $0.045(0.037)$ \\
\hline Bicycle & $0.009(0.036)$ & $-0.103 * *(0.049)$ & $-0.039(0.049)$ & $0.101 * *(0.043)$ & $0.032(0.044)$ \\
\hline \multicolumn{6}{|l|}{ Bus (reference) } \\
\hline \multicolumn{6}{|c|}{ Concern for climate change } \\
\hline $\begin{array}{l}\text { Very } \\
\text { threatening }\end{array}$ & $0.023(0.050)$ & $0.095^{*}(0.057)$ & $-0.095 *(0.050)$ & $0.041(0.051)$ & $-0.063(0.044)$ \\
\hline $\begin{array}{l}\text { Somewhat } \\
\text { threatening }\end{array}$ & $0.083 *(0.048)$ & $-0.0003(0.057)$ & $-0.037(0.048)$ & $0.052(0.050)$ & $-0.098 * *(0.043)$ \\
\hline \multicolumn{6}{|c|}{ Not threatening (reference) } \\
\hline$N$ & 767 & & & & \\
\hline Pseudo- $R^{2}$ & 0.0309 & & & & \\
\hline $\begin{array}{l}\text { Average class } \\
\text { probabilities }\end{array}$ & 0.7844 & 0.8588 & 0.9732 & 0.8110 & 0.9047 \\
\hline $\begin{array}{l}\text { Share of } \\
\text { respondents }\end{array}$ & $13.3 \%$ & $29.2 \%$ & $23.1 \%$ & $15.3 \%$ & $19.2 \%$ \\
\hline
\end{tabular}

Estimates report marginal effects. Robust standard error in parentheses. $* p<0.05 ; * * p<0.01 ; * * * p<0.001$ Average class probabilities and share of respondents obtained when identifying latent classes (AIC $=14427$, $\mathrm{BIC}=14741$ ) 


\section{References}

Alm J, Bloomquist KM, McKee M (2015) On the external validity of laboratory tax compliance experiments. Econ Inq 53(2):1170-1186

Anderson K (2012) The inconvenient truth of carbon offsets. Nat News 484(7392):7

Bain PG, Hornsey MJ, Bongiorno R, Jeffries C (2012) Promoting pro-environmental action in climate change deniers. Nat Clim Change 2(8):600-603

Bain PG, Milfont TL, Kashima Y, Bilewicz M, Doron G, Garð̋arsdóttir RB, Gouveia VV, Guan Y, Johansson L-O, Pasquali C, Corral-Verdugo V, Aragones JI, Utsugi A, Demarque C, Otto S, Park J, Soland M, Steg L, González R, Lebedeva N, Madsen OJ, Wagner C, Akotia CS, Kurz T, Saiz JL, Schultz PW, Einarsdóttir G, Saviolidis NM (2016) Co-benefits of addressing climate change can motivate action around the world. Nat Clim Change 6(2):154-157

Baranzini A, Bergh J, Carattini S, Howarth R, Padilla E, Roca J (2015) Seven reasons to use carbon pricing in climate policy. Working Paper wpdea1507, Department of Applied Economics at Universitat Autonoma of Barcelona

Baranzini A, Carattini S (2014) Taxation of emissions of greenhouse gases. In: Freedman B (ed) Global environmental change, number 1 in handbook of global environmental pollution. Springer, Dordrecht, pp 543-560

Baranzini A, Carattini S (2017) Effectiveness, earmarking and labeling: testing the acceptability of carbon taxes with survey data. Environ Econ Policy Stud 19(1):197-227

Baranzini A, Goldemberg J, Speck S (2000) A future for carbon taxes. Ecol Econ 32(3):395-412

Bornstein N, Lanz B (2008) Voting on the environment: Price or ideology? Evidence from Swiss referendums. Ecol Econ 67(3):430-440

Boyle KJ, Welsh MP, Bishop RC (1993) The role of question order and respondent experience in contingentvaluation studies. J Environ Econ Manag 25(1):S80-S99

Brannlund R, Persson L (2012) To tax, or not to tax: preferences for climate policy attributes. Clim Policy 12(6):704-721

Bristow AL, Wardman M, Zanni AM, Chintakayala PK (2010) Public acceptability of personal carbon trading and carbon tax. Ecol Econ 69(9):1824-1837

Bullock JG (2011) Elite influence on public opinion in an informed electorate. Am Polit Sci Rev 105(3):496515

Cameron TA, Englin J (1997) Respondent experience and contingent valuation of environmental goods. J Environ Eco Manag 33(3):296-313

Carattini S, Tavoni A (2016) How green are green economists? Econ Bull 36(4):2311-2323

Carattini S, Baranzini A, Roca J (2015) Unconventional determinants of greenhouse gas emissions: the role of trust. Environ Policy Gov 25(4):243-257

Carattini S, Baranzini A, Lalive R (2016) Is taxing waste a waste of time? Evidence from a supreme court decision. Working Paper 227, Grantham Research Institute on Climate Change and the Environment, LSE

Carattini S, Levin S, Tavoni A (2017) Cooperation in the climate commons. Technical report 259, Grantham Research Institute on Climate Change and the Environment, London

Cherry TL, Kallbekken S, Kroll S (2012) The acceptability of efficiency-enhancing environmental taxes, subsidies and regulation: an experimental investigation. Environ Sci Policy 16:90-96

Cherry TL, Kallbekken S, Kroll S (2014) The impact of trial runs on the acceptability of environmental taxes: experimental evidence. Resour Energy Econ 38(C):84-95

Chong D, Druckman JN (2011) Public-elite interactions-puzzles in search of researchers. In: Shapiro RY, Jacobs LR (eds) The Oxford handbook of American public opinion and the media. Oxford University Press, Oxford, pp 170-188

Conte MN, Kotchen MJ (2010) Explaining the price of voluntary carbon offsets. Clim Change Econ 1(2):93111

Czajkowski M, Hanley N, LaRiviere J (2015) The effects of experience on preferences: theory and empirics for environmental public goods. Am J Agric Econ 97(1):333-351

Deacon RT, Shapiro P (1975) Private preference for collective goods revealed through voting on referenda. Am Econ Rev 65(5):943-955

Deroubaix J-F, Lévèque F (2006) The rise and fall of French Ecological Tax Reform: social acceptability versus political feasibility in the energy tax implementation process. Energy Policy 34(8):940-949

Dresner S, Dunne L, Clinch P, Beuermann C (2006) Social and political responses to ecological tax reform in Europe: an introduction to the special issue. Energy Policy 34(8):895-904

Drews S, van den Bergh JCJM (2016) What explains public support for climate policies? A review of empirical and experimental studies. Clim Policy 16(7):855-876 
Druckman JN, Nelson KR (2003) Framing and deliberation: how citizens' conversations limit elite influence. Am J Polit Sci 47(4):729-745

Eagly AH, Chaiken S (1993) Psychology of attitudes. Cengage Learning, Fort Worth

Ecoplan (2012) Volkswirtschaftliche Auswirkungen einer ökologischen Steuerreform-Analyse mit einem berechenbaren Gleichgewichtsmodell für die Schweiz. Technical report, Bundesamt für Energie, Eidgenössische Steuerverwaltung und Eidgenössische Finanzverwaltung, Berne

Falk A, Heckman JJ (2009) Lab experiments are a major source of knowledge in the social sciences. Science 326(5952):535-538

Fankhauser S, Gennaioli C, Collins M (2015) Do international factors influence the passage of climate change legislation? Clim Policy 16(3):318-331

Fischel WA (1979) Determinants of voting on environmental quality: a study of a New Hampshire pulp mill referendum. J Environ Econ Manag 6(2):107-118

Fort R, Bunn DN (1998) Whether one votes and how one votes. Public Choice 95(1/2):51-62

Gevrek Z, Uyduranoglu A (2015) Public preferences for carbon tax attributes. Ecol Econ 118:186-197

Goulder LH (1995) Environmental taxation and the double dividend: a reader's guide. Int Tax Public Financ 2(2):157-183

Gowdy JM (2008) Behavioral economics and climate change policy. J Econ Behav Organ 68(3-4):632-644

Halbheer D, Niggli S, Schmutzler A (2006) What does it take to sell environmental policy? An empirical analysis of referendum data. Environ Resour Econ 33(4):441-462

Harrison GW, List JA (2004) Field experiments. J Econ Lit 42(4):1009-1055

Hart PS, Nisbet EC (2012) Boomerang effects in science communication: how motivated reasoning and identity cues amplify opinion polarization about climate mitigation policies. Commun Res 39(6):701-723

Howarth RB (2006) Optimal environmental taxes under relative consumption effects. Ecol Econ 58(1):209219

INFRAS (2015) Klimaschutz und Grüne Wirtschaft—was meint die Bevölkerung? Ergebnisse einer repräsentativen Bevölkerungsbefragung-Schlussbericht. Technical report, Bundesamt für Umwelt, Zurich

Ingold K, Varone F (2012) Treating policy brokers seriously: evidence from the climate policy. J Public Adm Res Theory 22(2):319-346

IPCC (2014) Fifth assessment report-mitigation of climate change. Technical report

Jacobsen GD (2011) The Al Gore effect: an inconvenient truth and voluntary carbon offsets. J Environ Econ Manag 61(1):67-78

Jordan AJ, Huitema D, Hildén M, Asselt H, Rayner TJ, Schoenefeld JJ, Tosun J, Forster J, Boasson EL (2015) Emergence of polycentric climate governance and its future prospects. Nat Clim Change 5(11):977-982

Kahan D, Wittlin M, Peters E, Slovic P, Ouellette L, Braman D, Mandel G (2011) The tragedy of the riskperception commons: culture conflict, rationality conflict, and climate change. SSRN Scholarly Paper ID 1871503, Social Science Research Network

Kahn ME (2002) Demographic change and the demand for environmental regulation. J Policy Anal Manag 21(1):45-62

Kahn ME, Matsusaka JG (1997) Demand for environmental goods: evidence from voting patterns on California initiatives. J Law Econ 40(1):137-174

Kallbekken S, Aasen M (2010) The demand for earmarking: results from a focus group study. Ecol Econ 69(11):2183-2190

Kallbekken S, Kroll S, Cherry TL (2010) Pigouvian tax aversion and inequity aversion in the lab. Econ Bull 30(3):1914-1921

Kallbekken S, Kroll S, Cherry TL (2011) Do you not like Pigou, or do you not understand him? Tax aversion and revenue recycling in the lab. J Environ Econ Manag 62(1):53-64

Kallbekken S, Sælen H (2011) Public acceptance for environmental taxes: self-interest, environmental and distributional concerns. Energy Policy 39(5):2966-2973

Kirchgassner G, Schneider F (2003) On the political economy of environmental policy. Public Choice 115(34):369-396

Kriesi H (2005) Direct democratic choice: the Swiss experience. Lexington, Lanham

Lakoff G (2010) Why it matters how we frame the environment. Environ Commun 4(1):70-81

Lenz GS (2012) Follow the leader? How voters respond to politicians' policies and performance. University of Chicago Press, Chicago

Lockwood M (2011) Does the framing of climate policies make a difference to public support? Evidence from UK marginal constituencies. Clim Policy 11(4):1097-1112

Longo A, Hoyos D, Markandya A (2012) Willingness to pay for ancillary benefits of climate change mitigation. Environ Resour Econ 51(1):119-140

Marcantonini C, Ellerman AD (2014) The implicit carbon price of renewable energy incentives in Germany. RSCAS Working Paper 2014/28, European University Institute 
Marchiori C, Dietz S, Tavoni A (2017) Domestic politics and the formation of international environmental agreements. J Environ Econ Manag 81:115-131

Mathys NA, de Melo J (2011) Political economy aspects of climate change mitigation efforts. World Econ 34(11):1938-1954

Metcalf GE (2009) Designing a carbon tax to reduce U.S. greenhouse gas emissions. Rev Environ Econ Policy 3(1):63-83

Millner A, Ollivier H (2016) Beliefs, politics, and environmental policy. Rev Environ Econ Policy 10(2):226244

Mohler L, Müller D (2012) Substitution elasticities in Swiss manufacturing. Technical report, Bundesamt für Energie, Berne

Murray B, Rivers N (2015) British Columbia's revenue-neutral carbon tax: a review of the latest "grand experiment" in environmental policy. Energy Policy 86:674-683

Myers TA, Nisbet MC, Maibach EW, Leiserowitz AA (2012) A public health frame arouses hopeful emotions about climate change. Clim Change 113(3-4):1105-1112

Nathani C, Sutter D, van Nieuwkoop R, Kraner S, Peter M (2011) Energiebezogene Differenzierung der Schweizerischen Input-Output-Tabelle. Technical report, Bundesamt für Energie, Berne

Nemet GF, Johnson E (2010) Willingness to pay for climate policy: a review of estimates. SSRN Scholarly Paper ID 1626931, Social Science Research Network

Oates WE, Portney PR (2003) The political economy of environmental policy. In: Vincent K-GMJR (ed) Handbook of environmental economics, volume 1 of environmental degradation and institutional responses. Elsevier, Amsterdam, North Holland, pp 325-354

Ostrom E (2009) A polycentric approach for coping with climate change. Policy Research Working Paper Series, The World Bank

Rocchi P, Serrano M, Roca J (2014) The reform of the European energy tax directive: exploring potential economic impacts in the EU27. Energy Policy 75:341-353

Sælen H, Kallbekken S (2011) A choice experiment on fuel taxation and earmarking in Norway. Ecol Econ 70(11):2181-2190

Salka WM (2001) Urban-rural conflict over environmental policy in the Western United States. Am Rev Public Adm 31(1):33-48

Sampei Y, Aoyagi-Usui M (2009) Mass-media coverage, its influence on public awareness of climate-change issues, and implications for Japan's national campaign to reduce greenhouse gas emissions. Glob Environ Change 19(2):203-212

Spash CL, Lo AY (2012) Australia's carbon tax: a sheep in wolf's clothing? Econ Labour Relat Rev 23(1):6785

Stadelmann-Steffen I (2011) Citizens as veto players: climate change policy and the constraints of direct democracy. Environ Polit 20(4):485-507

Steg L, Dreijerink L, Abrahamse W (2006) Why are energy policies acceptable and effective? Environ Behav 38(1):92-111

Thalmann P (2004) The public acceptance of green taxes: 2 million voters express their opinion. Public Choice 119:179-217

Tiezzi S, Xiao E (2016) Time delay, complexity and support for taxation. J Environ Econ Manag 77:117-141

Vöhringer F (2012) Linking the Swiss emissions trading system with the EU ETS: economic effects of regulatory design alternatives. Swiss J Econ Stat SJES 148(II):167-196

Whitehead JC, Blomquist GC, Hoban TJ, Clifford WB (1995) Assessing the validity and reliability of contingent values: a comparison of on-site users, off-site users, and non-users. J Environ Econ Manag 29(2):238-251

World Bank (2014) State and trends of carbon pricing 2014. Technical report

Zaller JR (1992) The nature and origins of mass opinion. Cambridge University Press, Cambridge 